Review Article

\title{
Adopting Building Information Modeling (BIM) for the Development of Smart Buildings: A Review of Enabling Applications and Challenges
}

\author{
Ang Yang $\mathbb{D}^{1},{ }^{1}$ Mingzhe Han $\left(\mathbb{D},{ }^{1}\right.$ Qingcheng Zeng, ${ }^{1}$ and Yuhui Sun $\mathbb{D}^{2}$ \\ ${ }^{1}$ School of Maritime Economics and Management, Dalian Maritime University, Dalian 116026, China \\ ${ }^{2}$ UniSA STEM, University of South Australia, Adelaide, SA 5001, Australia \\ Correspondence should be addressed to Yuhui Sun; yhsun0530@gmail.com
}

Received 15 September 2020; Revised 5 February 2021; Accepted 18 February 2021; Published 10 March 2021

Academic Editor: Hexu Liu

Copyright (c) 2021 Ang Yang et al. This is an open access article distributed under the Creative Commons Attribution License, which permits unrestricted use, distribution, and reproduction in any medium, provided the original work is properly cited.

The construction industry is undergoing a digital revolution due to the emergence of new technologies. A significant trend is that construction projects have been transformed and upgraded to the digital and smart mode in the whole life cycle. As a critical technology for the construction industry's innovative development, building information modeling (BIM) is widely adopted in building design, construction, and operation. BIM has gained much interest in the research field of smart buildings in recent years. However, the dimensions of BIM and smart building applications have not been explored thoroughly so far. With an in-depth review of related journal articles published from 1996 to July 2020 on the BIM applications for smart buildings, this paper provides a comprehensive understanding and critical thinking about the nexus of BIM and smart buildings. This paper proposes a framework with three dimensions for the nexus of BIM application in smart buildings, including BIM attributes, project phases, and smart attributes. According to the three dimensions, this paper elaborates on (1) the advantages of BIM for achieving various smartness; (2) applications of BIM in multiple phases of smart buildings; and (3) smart building functions that be achieved with BIM. Based on the analysis of the literature in three dimensions, this paper presents the cross-analysis of the nexus of BIM and smart buildings. Lastly, this paper proposes the critical insights and implications about the research gaps and research trends: (1) enhancing the interoperability of BIM software; (2) further exploring the role of BIM in the operation and refurbishment phase of smart buildings; (3) paying attention to BIM technology in the field of transportation infrastructure; (4) clarifying the economic benefits of BIM projects; and (5) integrating BIM and other technologies.

\section{Introduction}

Smart buildings have become the inevitable trend of future buildings [1]. The concept of smart buildings derives from the continuous integration of advanced information technology with buildings and their systems, which enables buildings to be operated and controlled remotely throughout the lifecycle in a convenient, comfortable, costsaving, and energy-saving manner. The goal of smart buildings is to provide safe, energy-saving, environmentally friendly, and convenient services. In order to achieve smartness, smart buildings should make smart decisions with the support of information technologies, such as building information modeling (BIM), sophisticated machine learning, and big data [2]. BIM has been one of the most significant advanced technologies in construction and widely adopted in the construction industry in recent years [3]. BIM uses computers to create virtual 3D models and integrates project-related relevant information, allowing all project participants to understand the various phases of the building quickly. Using BIM has a wide range of benefits, including reducing project cost, shortening construction time, and improving project quality $[4,5]$. Therefore, the understanding of BIM technology applications in the construction field is necessary for the development of smart buildings.

There have been a relatively large amount of studies on supporting technologies of smart buildings recently, such as 
IoT, big data, and machine learning. For example, Jia et al. [6] discussed the application of IoT in the development of smart buildings. Plageras et al. [7] designed and simulated a topology-architecture system of smart buildings by investigating the IoT, cloud computing, big data, and sensor technologies. Qolomany et al. [2] reviewed the potential uses of machine learning for smart building services. Although information technology-based surveys on smart buildings have existed, research on how BIM can support smart buildings is still lacking.

With the continuous exploration of the potential value of BIM, the application of BIM in various fields of building management is also expanding, such as schedule management (4D) [8], cost management (5D) [9], energy management (6D) [10], and facility management (7D) [11]. The application of BIM is an essential part of the research of smart buildings. The realization of the application based on BIM requires the integration of BIM with other disciplines. However, many issues require further research in the process of the integration of BIM with other disciplines. For example, the current software solutions are not mature enough and lack interoperability in the process of $4 \mathrm{D}$ simulation, which leads to the challenge in centralized management of building information [8]. For life cycle cost optimization with BIM across multidisciplinary, the lack of interoperability also exists among multiple levels, such as systems, tools, and data [9]. In terms of energy management, Gerrish et al. [10] summarized the challenges related to the process, skills, and technology, when BIM was applied to build energy performance management. The challenges of energy performance management based on BIM include the limited understanding of BIM by project members, the lack of experienced BIM implementers, and the lack of clear standards and regulations to promote the BIM implementation [10]. In terms of facility management, BIM-based facility operation and maintenance still face challenges [11]. The challenges of facility management based on BIM include insufficient interoperability, lack of understanding of the basic operation and maintenance principles of BIM implementation, and unclear investment returns. However, the BIM implementation challenges proposed by different researchers are not comprehensive due to the different research focuses of various researchers. Existing research studies still lack challenge analysis in the application process of BIM in smart buildings from a comprehensive and systematic perspective. This paper focuses on the enhanced functions and the challenges of adopting BIM in smart buildings, rather than just referring to the BIM challenges in a specific application or the technical defects of BIM.

Based on the above considerations, this paper aims to answer the following two research questions: (1) What is the nexus of BIM and smart buildings? (2) What are the challenges in the application of BIM in smart buildings?

The motivation of this paper is taken from the requirement of smart buildings and the development trend of BIM. On the one hand, smart buildings require a wide range of technologies to support. On the other hand, BIM is regarded as one of the most critical advances in the construction industry. Therefore, the purpose of this study is to provide a comprehensive and up-to-date literature review on the application of BIM in the field of smart buildings. This paper aims to contribute to the construction of knowledge systems of BIM in the field of smart buildings and further inspire researchers and stakeholders to explore the development of BIM technology in the field of smart buildings. The specific research objectives of this paper are to summarize the current status of BIM's research studies and applications in the field of smart buildings and analyze the challenges encountered in the research process and future research directions.

This paper is structured as follows. Section 1 briefly reviews the application requirements of BIM in smart buildings and proposes research motivation and goal. Section 2 designs the research method of this paper. Section 3 discusses the nexus of BIM and smart buildings, focusing on the summary of the latest BIM function to solve various issues about smartness in the field of smart buildings, the life cycle of BIM-supported smart buildings, and the applications of BIM in smart buildings. Section 4 analyzes the challenges faced by BIM in the application of smart buildings and proposes future research directions. Finally, Section 5 concludes the paper.

\section{Research Methodology}

2.1. Concepts of Smart Buildings and BIM. Neither smart buildings nor BIM has a unified and clear concept currently. This section analyzes the concepts of smart buildings and BIM proposed by other scholars so as to put forward the definition of smart buildings and BIM in this paper.

The concept of smart buildings dates back to the United States in the early 1980s [12]. The Intelligent Building Institute (IBI) of the United States described smart buildings could integrate various systems to manage resources in a cooperative mode to maximize effectively technical performance, investment and operating cost-savings, and flexibility [12] (1988, cited in Refs. [13]). The definition puts forward some operative assumptions about the functions of smart buildings in the future. Based on the definition proposed by the Smart Building Institute (IBI), other new definitions of smart buildings are formed. European Intelligent Building Group (EIBG) proposed that smart buildings need to create an environment that can fully improve the efficiency of building occupants and achieve efficient resource management with the lowest cost of hardware and facility life (2002, cited in Refs. [14, 15]). EIBG definition comes from a building performance perspective, focusing on reducing life cycle costs and enhancing resource control.

Later, the definition of smart buildings comes to be associated with the experience of the occupant. The Chinese IB Design Standard (GB/T50314-2000) considered the building as the platform, equipped with building automation, office automation, and communication network system, and integrated the optimal combination of structure, system, service, and management, to provide users with an efficient, comfortable, convenient, and safe building environment [12]. Li [16] proposed that smart buildings integrate construction equipment, office automation and 
communication network, structure optimization, service, and management into one system to provide people with a safe, efficient, comfortable, and convenient building environment. Since increasing the functions of smart buildings is essential, it is critical to define smart buildings from the aspects of various smart functions. Referring to the existing definitions of smart buildings, this paper regards smart buildings as future buildings that can realize sustainable building value and meet users' needs based on various advanced technologies.

The construction industry initially uses computer-aided design (CAD) for 2D design. The concept of building information modeling (BIM) has been introduced into the construction industry to solve the problem of data exchange between CAD and analysis systems [4, 17]. Barlish and Sullivan [18] defined BIM as a smart 3D virtual building model that digitizes all building information and is constructed into a smart format (2010, cited in Refs. [18]). Such smart format is used for developing optimized building solutions with reduced risk and added value before submission of design proposals. Isikdag and Underwood [17] defined that BIM is a new way to create, share, exchange, and manage information in the whole building life cycle. Yin et al. [19] proposed BIM is a parametric design tool for the digital representation of construction projects and an information-sharing platform for supporting collaboration among project team members and various stakeholders. While several relevant definitions of BIM have been established, for this paper, BIM is defined as an information modeling technology to promote safe, green, energy-saving, and comfortable buildings by integrating all information of the project's whole life cycle. The BIM concept of this study is considered in the context of a smart building environment and emphasizes on building information throughout the project's full life cycle.

In the process of defining smart buildings and BIM, this paper summarizes the relevant keywords of two definitions: (1) "smart buildings" [12], "smart building*" [20,21], and "Smart construction" [22]; (2) "BIM" [23] and "building information model*" [17, 24-26]. These keywords are used because they have similar meanings. It should be noted that the wildcard* is used to capture related variations of the word [26], such as "smart building," "smart buildings," or "building information model," "building information modelling (BIM)," "building information modeling," and "Building Information Models." These keywords help to obtain a complete literature database in the literature search in Section 2.2 .

2.2. Literature Search and Selection Strategy. The specific selection process of literature refers to the methods of other review articles, such as [26-28]. The literature screening process is commonly used in review articles, including determining the literature database and retrieval rules, preliminary search, and literature screening stages. This paper divides the literature collection and screening into the following four stages (see Figure 1).

(1) In the stage of literature collection, four retrieval standards are established:

(i) The selection of the file type. In order to ensure the reliability and rigor of the review results, many articles only review articles published in peer-reviewed academic journals. These articles are considered to be of higher quality than conference papers, so this paper only includes peer-reviewed articles in English journals.

(ii) The selection of the database. SCI and SSCI in the core database of WOS are selected to collect journal articles. The journal articles in the core database are the reliable sources of research studies on the development of BIM-based smart buildings. The method of collecting journal articles from SCI and SSCI in the WOS core database has been used by other researchers [27].

(iii) The selection of keywords. Based on the summary in Section 2.1, the search keywords in this paper include smart building, smart building*, Smart construction, BIM, and Building information model $*$. The rule is $(\mathrm{TS}=$ smart building OR TS $=$ smart build $*$ OR TS $=$ Smart con struction) AND $(\mathrm{TS}=\mathrm{BIM}$ OR TS $=$ Building information model $*$ ).

(iv) The selection of research categories. According to the research topic, the search was further refined by selecting WOS categories (Engineering civil, Construction building technology, and Green sustainable science technology).

In this stage, 223 articles were searched as the initial literature search outcomes.

(2) In the preliminary literature screening stage, we conduct preliminary screening according to the literature analysis report obtained in the previous stage of WOS.

(i) The selection of the publication time period. In order to obtain a sufficiently broad sample of cited articles, we do not limit the year specifically. The earliest relevant article appears in 1996 in the first stage, so this paper selects the articles published from 1996 to July 7, 2020 [29].

(ii) The selection of journals. This step draws on the journal selection method proposed by Zheng et al. [30]. The results of the first stage show that the journals with the highest number of papers published are as follows: Automation in Construction, Energy and Buildings, Sustainability, IEEE Transactions on Intelligent Transportation, Journal of Cleaner Production, Sustainable Cities and Society, Building and Environment, 


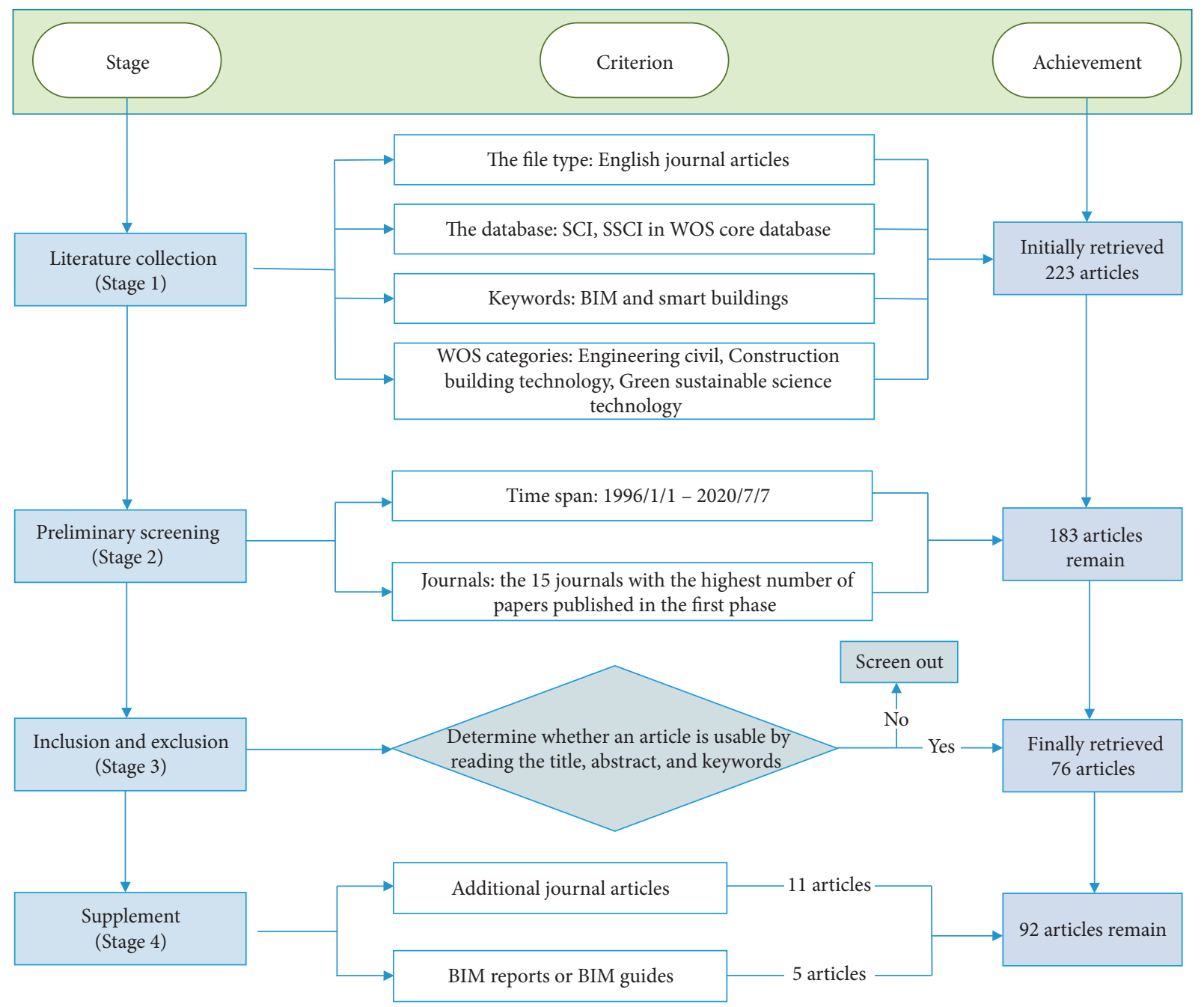

FIGURE 1: Literature research retrieval and selection strategy.

Transportation Research Record, Journal of Computing in Civil Engineering, Engineering Construction and Architectural Management, Journal of Management in Engineering, Computer-Aided Civil and Infrastructure Engineering, Journal of Building Engineering, KSCE Journal of Civil Engineering, and Renewable Energy. According to the number of papers published, we selected the top 15 journals (the journals with more than three papers published) as the target journals in the second stage.

After the exclusion of 40 articles in the second stage, we get 183 results.

(3) Inclusion and exclusion of literature. Identify irrelevant articles by reading titles, abstracts, and keywords. In order to describe the scope and characteristics of BIM applications in smart buildings, this paper follows the definitions of smart buildings and BIM in Section 2.1, thus providing critical criteria for the selection of academic articles.
After removing 107 papers with low correlation and no correlation, 76 papers were left for further analysis.

(4) The supplement of BIM reports and guidance documents. In the process of exploring the nexus of BIM and smart buildings, some articles related to this research may have been filtered out due to the choice of databases and document types. Therefore, this paper adds several high practical value references, including 11 articles and 5 BIM reports or guidelines. The added literature contains well-known early publications and highly relevant recently published articles on BIM and smart buildings. The journal articles are sourced from the public database Google Scholar, and the reports and guides are sourced from famous companies or research centers such as Boston Consulting Group (BCG), Alibaba Group, and The National Institute of Building Sciences. A total of 16 literature articles are added to the fourth stage, and 92 articles are selected for further analysis. 
Section 2.2 describes in detail the literature screening strategy for this paper. The results of the screening are presented below. Table 1 shows the journal information of the selected literature. Figure 2 shows the number of relevant literature studies published from 2005 to 2020 .

2.3. The Combination of BIM and Smart Buildings. With the continuous development of BIM and smart buildings, smart BIM technology has been proposed. de Vries et al. [31] proposed that smart BIM is composed of a smart design system using smart technologies. The application of a smart design system requires smart BIM, which is a model containing smart objects and user tasks. There are no mature research frameworks of smart BIM currently, but some scholars have proposed a relatively perfect framework of green BIM in the field of green building. According to the Green BIM Triangle proposed by Lu et al. [32], this paper proposes the concept of smart BIM to describe the relation of BIM and smart buildings. Smart BIM refers to the combination of BIM and smart buildings. BIM attributes represent the key features of BIM. Project phases and smart attributes describe smart buildings. Therefore, the interaction between BIM and smart buildings gives rise to three dimensions, including BIM attributes, project phases, and smart attributes.

2.3.1. BIM Attributes. Attributes of BIM represent the function that BIM technology can provide for smart buildings. Existing studies show that key functions of BIM include integrating information, visualizing models, facilitating collaboration, and other additional functions.

Firstly, BIM can be combined with other systems to realize more BIM application functions. For example, Jalaei and Jrade [33] developed a model that combines BIM with the Canadian green building certification system (LEED) and sustainable building cost estimation. The BIM and LEED integration model was linked to the BIM tool Revit as a plug-in [33]. All available data in the model, such as project information and LEED parameters for building components, are stored in an external database connected to the BIM tool. The plug-in helps project teams make sustainability-related decisions by providing designers with the information they need. Göçer et al. [34] proposed an integrated model combining BIM and GIS. The integrated model used photogrammetry and BIM tools to generate the as-is 3D geometric model and uses GIS to analyze and visualize the as-is data on the 3D model [34]. The 3D model enables the effective acquisition and integration of various forms of building data and realizes the visualization and analysis of building data mapping.

Secondly, BIM is used as the information center of the project life cycle to share and exchange information [17]. For example, Oh et al. [35] proposed a collaborative design integration system based on the development of three submodules. Three submodules contain BIM modeler, BIM checker, and BIM server [35]. The collaborative design integration system improves design quality and work efficiency.
TABLE 1: Distribution of selected journal literature.

\begin{tabular}{lc}
\hline Journal title & $\begin{array}{c}\text { Number of selected } \\
\text { papers }\end{array}$ \\
\hline Automation in Construction & 36 \\
Journal of Cleaner Production & 7 \\
Sustainability & 7 \\
Building and Environment & 5 \\
Journal of Computing in Civil Engineering & 5 \\
Energy and Buildings & 4 \\
Procedia Engineering & 4 \\
Engineering Construction and & 3 \\
Architectural Management & 3 \\
Journal of Management in Engineering & 3 \\
KSCE Journal of Civil Engineering & 3 \\
Sustainable Cities and Society & 2 \\
Computer-Aided Civil and Infrastructure & 2 \\
Engineering & 1 \\
Journal of Building Engineering & \\
IEEE Transactions on Intelligent & 1 \\
Transportation Systems & 1 \\
International Journal of Project & 5 \\
Management & 92 \\
Transportation Research Record &
\end{tabular}

Thirdly, the essential function of BIM technology is the visualization of the BIM model. For example, Röck et al. [36] used BIM models to assess building schemes and their environmental impacts and achieve the visualization of life cycle assessment (LCA) results in communication and design guidance.

Fourth, the distinct feature of BIM technology is the analysis and simulation function. A variety of building energy modeling tools (OpenStudio and EnergyPlus) can import BIM files for energy simulation [37]. For example, based on the full release of BIM simulation potential, Pinheiro et al. [38] used Industry Foundation Classes (IFC) as input for energy simulation software. They proposed a standardized method for information exchange between BIM and building energy performance simulation (BEPS) tools to reduce the time and cost associated with model creation [38].

Based on the above research, this paper summarizes BIM attributes. At the same time, this study refers to the BIM attributes proposed by $\mathrm{Lu}$ et al. [32], including integration with various databases, and facilitates document management, visualization of analysis processes and results, sustainability analysis, and simulation. Therefore, this paper summarizes "BIM attributes" as four aspects: (1) the integration with other systems; (2) the convenience of information sharing and exchange; (3) the visualization of the whole process and results; and (4) the analysis and simulation of building functions.

2.3.2. Project Phases. The dimension of the "project phases" discusses the application of BIM technology in the field of smart buildings from the perspective of the project life cycle. Any construction project goes through a full life cycle, from 


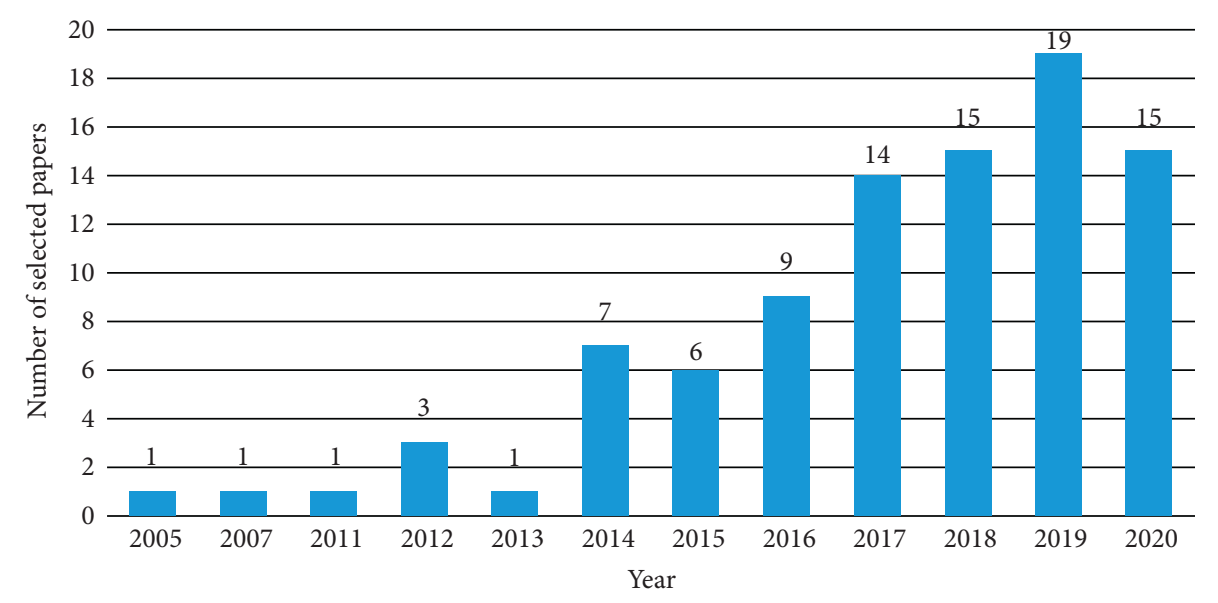

Figure 2: Number of relevant literature studies published yearly from 2005 to 2020.

project planning to design, construction, operation and maintenance, and finally to refurbishment and demolition.

Different studies have different understandings of the life cycle of building projects due to different research contents. For instance, according to the risk management process, Zou et al. [39] divided the project phases into the planning and design phase, the construction phase, the use and maintenance phase, and the demolition phase. According to the definition of BIM, Ding et al. [40] divided the project life cycle into the planning phase, the design phase, the construction phase, and the operation phase. Considering the combination of BIM and sustainability, Chong et al. [41] divided the project life cycle into seven categories: planning, design, construction, operation and maintenance, refurbishment and demolition, use of products and materials, and energy consumption.

The main content of this paper is the combination of BIM and smart buildings. Most of the predictable smart functions should be considered during the building planning or design phase. In contrast, other smart functions should be managed and further developed during the construction and subsequent phases. Therefore, this paper divides the project phases into the planning and design phase, the construction phase, and the operation and maintenance phase.

2.3.3. Smart Attributes. Smart attributes come from the understanding of smart buildings' features. According to the White Paper on Smart Buildings released by Alibaba Group, the feature of smart buildings includes four aspects: environment, economy, user experience, social culture, and technological innovation [42]. In order to realize the smart features of smart buildings, it is necessary to use a variety of emerging information technologies to improve the building environment and the functions of occupants, allocate resources, and control costs reasonably. Therefore, this paper considers smart attributes at four aspects: reducing energy consumption, increasing economic benefits, improving users' life quality, and combining with other technologies.

\section{The Nexus of BIM and Smart Buildings}

The combination of BIM and smart buildings constitutes smart BIM. The smart BIM framework represents the threedimensional nexus view of BIM and smart buildings. The nexus of BIM and smart buildings consists of three aspects: (1) how BIM supports various smart issues; (2) how BIM supports the different phases of smart buildings; and (3) whether various functions of smart buildings can be realized through BIM. The three aspects are not independent of each other but should be combined and integrated for the smart applications. Achieving the maximum potential of BIM in smart buildings requires cross-analysis of these three aspects.

Section 3 elaborates the nexus of BIM and smart buildings in terms of three dimensions and then conducts cross-analysis on the three dimensions. Figure 3 shows a 3D view of the nexus of BIM and smart buildings. Firstly, in Section 3.1, the specific functions of BIM that support various smart building functions are represented with BIM attributes $(X)$. BIM attributes $(X)$ are presented in Section 2.3.1, including integration with other systems $\left(X_{1}\right)$, the convenience of information sharing and exchange $\left(X_{2}\right)$, visualization of the whole process and results $\left(X_{3}\right)$, and analysis and simulation of building functions $\left(X_{4}\right)$. Secondly, in Section 3.2, the application of BIM technology in the various phases of the smart building project life cycle is discussed from the perspective of the smart buildings' project phases $(Y)$. According to Section 2.3.2, smart buildings' project phases $(Y)$ are divided into the planning and design phase $\left(Y_{1}\right)$, the construction phase $\left(Y_{2}\right)$, and the operation and maintenance phase $\left(Y_{3}\right)$. Thirdly, in Section 3.3, the BIM-based smart building functions are represented by smart attributes $(Z)$. Smart attributes $(Z)$ are proposed in Section 2.3.3, including reducing energy consumption $\left(Z_{1}\right)$, increasing economic efficiency $\left(Z_{2}\right)$, improving users' quality of life $\left(Z_{3}\right)$, and combining with other technologies $\left(Z_{4}\right)$. Finally, in Section 3.4, this paper performs the cross-analysis of three dimensions regarding various BIM and smart building applications. 


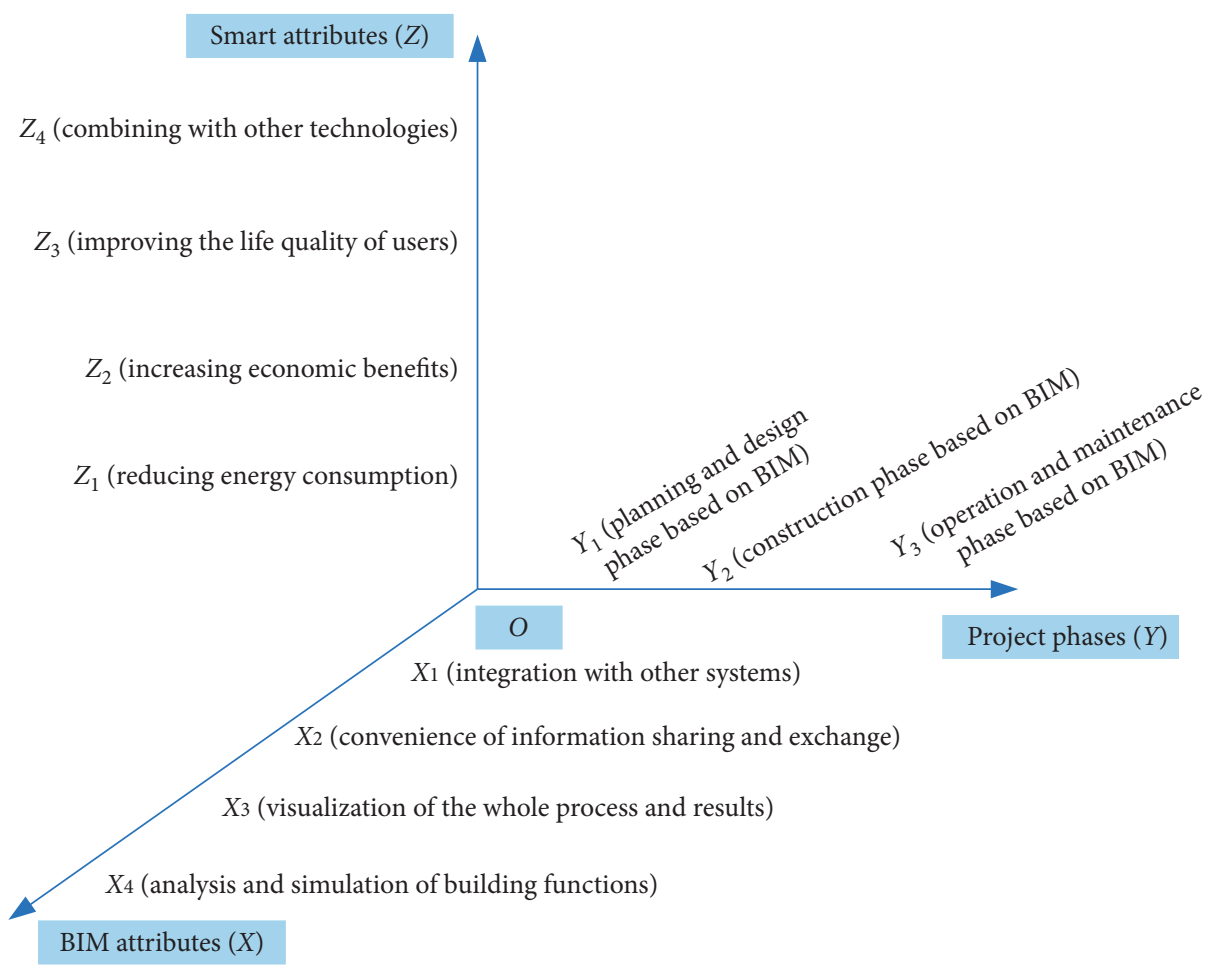

Figure 3: A 3D view of the nexus of BIM and smart buildings.

3.1. BIM Functions for Major Smart Issues. Applications of BIM functions in the field of smart buildings are discussed widely. First, BIM can meet the need of building smartness by integrating with other information management systems. BIM solves the problem of "information islands" and realizes the effective transmission and sharing of building information among all project participants. BIM also improves the decision-making efficiency of the whole project by applying the visualization function to various aspects such as pipeline collision detection, energy consumption assessment, and emergency management. Moreover, using BIM technology can analyze and simulate the whole process of the project, allocate resources rationally, optimize the construction sequence, and avoid rework and waste.

3.1.1. Integration with Other Systems $\left(X_{1}\right)$. With the gradual deepening of BIM applications, the simple application of BIM in smart building projects has become uncommon. BIM is more about integrating with other systems to play a more excellent comprehensive value.

First, BIM can be integrated with energy management systems $\left(X_{1}\right)$ to realize building energy data sharing for smart decisions, such as fault detection and demand response. For example, Woo and Menassa [43] developed a software prototype to connect a building to a smart grid environment. The software prototype combined BIM and EMCS (Energy Management Control System) $\left(X_{1}\right)$ to enable the building as a smart grid terminal node to communicate with the smart grid [43]. Second, BIM can be integrated with the manufacturing system $\left(X_{1}\right)$ to determine whether the machine can use BIM software to produce predesigned building products. For example, An et al. [44] integrated BIM and manufacturing systems $\left(X_{1}\right)$, proposing an automatic evaluation machine capability framework based on BIM. Third, integrating BIM and GIS (Geographical Information System) $\left(X_{1}\right)$ can provide various application managements for smart buildings, such as data integration, quantitative analysis, and spatial management. For example, Marzouk and Othman [45] put forward a framework combining BIM and GIS $\left(X_{1}, Z_{4}\right)$ to plan and predict the public infrastructure requirements for emerging cities $\left(Y_{1}\right)$. Fourth, BIM can be integrated with BAS (building automation system) $\left(X_{1}\right)$ for energy management $\left(Z_{1}\right)$, building design optimization and operation $\left(Y_{1}, Y_{3}\right)$, and building fault detection and diagnosis. BAS is one of the main components of smart buildings, which is mainly applied in facility management [46]. Tang et al. [46] used BIM tools to assist BAS in information exchange $\left(X_{2}\right)$ of design and operation at different stages of the project $(Y)$. The authors defined an IFC (Industry Foundation Class) subset schema and then showed the IFC subset pattern for BAS information exchange between BIM and facility management tools [46].

3.1.2. Convenience of Information Sharing and Exchange $\left(X_{2}\right)$. The realization of smart buildings is inseparable from the efficient processing and application of building information. Emerging of BIM technology not only provides models containing various kinds of information but also realizes the sharing and exchange of existing information $\left(X_{2}\right)$ based on models. For example, Keskin and Salman [47] used the information model provided by BIM to share and exchange information $\left(X_{2}\right)$. This model enables the 
increasing demand for digitalization throughout the life cycle of buildings and enables project stakeholders to access, manage, use, and connect physical and operational data in a digitalized collaborative environment. Tang et al. [46] also used BIM to facilitate BAS information exchange and integration $\left(X_{2}\right)$. The authors defined an IFC subset schema (A BACnet MVD) and used Revit and a web browser to demonstrate the implementation of BACnet MVD for the BAS information exchange [46]. In this way, BAS information represented by the open BIM standard can realize the potential of smart buildings' information exchange and integration in the future. In addition to realizing information sharing and exchange $\left(X_{2}\right)$, Li et al. [48] proposed that BIM can also effectively promote information security. $\mathrm{Li}$ et al. [48] proposed a smart BIM platform highly dependent on information. The platform emphasizes that only authorized stakeholders can access information to ensure information security.

3.1.3. Visualization of the Whole Process and Results $\left(X_{3}\right)$. Visualization is one of the most significant advantages of BIM. Visualization is not merely a simple $3 \mathrm{D}$ model, but a 3D model with the building information to realize certain building functions. BIM presents real building components in the form of $3 \mathrm{D}$ visual models $\left(X_{3}\right)$. Therefore, both designers and other project participants can see the real doors, windows, ceilings, and other components, so that they can understand the whole project more clearly. Current research studies suggest that the $3 \mathrm{D}$ visualization function of BIM can be applied to building performance analysis, emergency management, and construction site management $\left(Y_{2}\right)$ of smart buildings.

First, BIM can make full use of visual data for building performance analysis $\left(X_{3}\right)$. For example, Han and Golparvar-Fard [49] discussed the strategy of using emerging visual big data and BIM $\left(Z_{4}\right)$ to capture, analyze, and report visual data in construction performance monitoring $\left(Y_{2}\right)$ and introduced a visual analysis method based on image and BIM. This method needs to select the correspondence between visual data and BIM, which can use BIM to align a set of disordered images.

Second, BIM technology can display three-dimensional sites and help users visualize fire, earthquakes, and other emergencies, improving the accuracy and effectiveness of disaster response decision-making significantly. For example, Cheng et al. [50] used BIM to build a disaster prevention system framework that displays real-time and dynamic three-dimensional fire information $\left(X_{3}\right)$. The framework uses BIM technology to display the flame area, helping users visualize the fire situation.

Third, construction site management also benefits from the $3 \mathrm{D}$ visualization function of BIM technology. Hundreds of images and videos are captured during construction. This BIM-related visual data needs to be further localized to provide useful and accurate construction status [49]. In consideration of the health and safety of workers in the construction site, Riaz et al. [51] proposed a limited space monitoring system based on wireless sensor network (WSN) and $\operatorname{BIM}\left(Z_{4}\right)$ to monitor the enclosed space effectively in the construction site $\left(Y_{2}\right)$. The system used Autodesk Revit software to present the data received from the WSN in a confined space on a construction site [51]. The data include oxygen, temperature, energy consumption, and other values inside the space. Managers can retrieve the latest sensor data stored in a central database at any time to deal with hazards in confined spaces if needed. Dutta et al. [52] also applied BIM technology to construction site management $\left(\mathrm{Y}_{2}\right)$ from the perspective of the equipment rather than from the perspective of construction personnel. The research realizes the automatic replanning of the lifting path of the tower crane on the construction site. This is mainly due to a reprogramming module developed by the Nanyang Technological University for the Computer-Aided Lift Planning (CALP) system.

3.1.4. Analysis and Simulation of Building Functions $\left(X_{4}\right)$. The analysis and simulation function of BIM $\left(X_{4}\right)$ in smart buildings refers to the BIM functions of simulating and analyzing real events in building models before the actual project starts. Olawumi and Chan [53] used a Delphi survey to determine that a significant advantage of integrating BIM and sustainable development practices is the ability to simulate building performance and energy use. Through the analysis and simulation of building functions $\left(X_{4}\right)$, BIM technology can reduce or even avoid conflicts, errors, wastes, and risks, which further realize the wisdom of building functions. Therefore, in order to realize the intelligence of building functions, project managers need to analyze and simulate the building energy consumption, user comfort, building safety, and other functions.

Existing studies show that BIM technology can simulate the analysis of building functions $\left(X_{4}\right)$ as follows (see Table 2). First, in the planning and design phase $\left(Y_{1}\right)$, BIM can be used for daylighting simulation [54] $\left(Z_{3}\right)$ and security analysis [55] $\left(Z_{3}\right)$. Second, in the construction phase $\left(Y_{2}\right)$, BIM can be used for earned value management [56] $\left(Z_{2}\right)$, cost/schedule estimation [57] $\left(Z_{2}\right)$, and construction safety analysis [58] $\left(Z_{3}\right)$. Third, in the operation and maintenance phase $\left(Y_{3}\right)$, BIM can be used for daily management and emergency simulation analysis, such as energy simulation [43] $\left(Z_{1}\right)$, user daily activity simulation [59] $\left(Z_{3}\right)$, indoor environmental quality analysis $[60]\left(Z_{3}\right)$, and fire personnel evacuation simulation [50] $\left(Z_{3}\right)$.

Compared with general buildings, BIM has realized more functions and advantages in smart buildings. It is helpful to consider the different levels of BIM usage. At the first level, the project uses 3D, BIM-based computer-aided design (CAD) software, and collision detection tools for the basic design of the project. However, all actual blueprints are produced in a traditional way. Each company in the project processes data independently and has a manual interface with the BIM platform [61]. At the second level, the project began to exchange some information using the common BIM file format to assist the project in schedule management (4D) and cost management (5D). At the third level, BIM can be further expanded to include energy management (6D), 
TABLE 2: BIM-supported analysis and simulation functions of smart buildings.

\begin{tabular}{|c|c|c|c|c|c|}
\hline $\begin{array}{l}\text { Analyze/simulate } \\
\text { functions }\end{array}$ & Project phases & Study description & Outcomes & Key technologies & References \\
\hline $\begin{array}{l}\text { Daylighting } \\
\text { simulation }\end{array}$ & $\begin{array}{l}\text { Planning and } \\
\text { design }\end{array}$ & $\begin{array}{l}\text { This paper presents a methodology } \\
\text { for automated product model } \\
\text { decomposition and recomposition } \\
\text { for climate-based daylighting } \\
\text { simulation using Radiance }\end{array}$ & $\begin{array}{l}\text { Methodology for the } \\
\text { automated product } \\
\text { model }\end{array}$ & $\begin{array}{l}\text { Revit, ThermalSim } \\
\text { AMS }\end{array}$ & {$[54]$} \\
\hline Safety analysis & $\begin{array}{l}\text { Planning and } \\
\text { design }\end{array}$ & $\begin{array}{l}\text { The study performs static and } \\
\text { dynamic security analysis with the } \\
\text { aid of BIM }\end{array}$ & Application of graphing & $\begin{array}{l}\text { Revit, Rooms, Rock, } \\
\text { Explosive }\end{array}$ & {$[55]$} \\
\hline $\begin{array}{l}\text { Earned value } \\
\text { management }\end{array}$ & Construction & $\begin{array}{c}\text { This paper presents the use of BIM } \\
\text { in the cost and time management } \\
\text { of infrastructure bridges }\end{array}$ & $\begin{array}{l}\text { BIM-based cost } \\
\text { estimation application }\end{array}$ & $\begin{array}{l}\text { MS Excel, Tekla } \\
\text { Structures }\end{array}$ & {$[56]$} \\
\hline $\begin{array}{l}\text { Cost/schedule } \\
\text { estimation }\end{array}$ & Construction & $\begin{array}{l}\text { The research builds a system of a } \\
3 \mathrm{D} \text { intelligent model to predict } \\
\text { highway construction cost and } \\
\text { duration. }\end{array}$ & $\begin{array}{l}\text { Model for construction } \\
\text { planning/Simulation }\end{array}$ & $\begin{array}{l}\text { Revit, AutoCAD Civil } \\
\text { 3D, Trimble SketchUp }\end{array}$ & {$[57]$} \\
\hline $\begin{array}{l}\text { Safety clash } \\
\text { detection }\end{array}$ & Construction & $\begin{array}{l}\text { This paper identifies safety } \\
\text { incompatibilities among } \\
\text { fundamental attributes using data } \\
\text { mining }\end{array}$ & $\begin{array}{l}\text { Conceptual framework } \\
\text { and processing system }\end{array}$ & $\begin{array}{l}\text { Graph mining, } \\
\text { hierarchical clustering } \\
\text { on principal } \\
\text { components (HCPC) }\end{array}$ & {$[58]$} \\
\hline $\begin{array}{l}\text { Energy } \\
\text { performance } \\
\text { simulation }\end{array}$ & $\begin{array}{l}\text { Operation and } \\
\text { maintenance }\end{array}$ & $\begin{array}{l}\text { This paper provides a virtual } \\
\text { retrofit model for aging } \\
\text { commercial buildings in a smart } \\
\text { grid environment }\end{array}$ & $\begin{array}{l}\text { The framework of the } \\
\text { Virtual Retrofit Model } \\
\text { (VRM) }\end{array}$ & $\begin{array}{l}\text { Revit, 3D point clouds, } \\
\text { Cyclone, AutoCAD, } \\
\text { sensors, Google Map }\end{array}$ & {$[43]$} \\
\hline $\begin{array}{l}\text { User daily activity } \\
\text { simulation }\end{array}$ & $\begin{array}{l}\text { Operation and } \\
\text { maintenance }\end{array}$ & $\begin{array}{l}\text { This paper does a prototyping } \\
\text { experiment with three typical } \\
\text { domestic tasks and several real- } \\
\text { time interactions }\end{array}$ & Smart design system & $\begin{array}{l}\text { Virtual reality (VR), } \\
\text { CAD }\end{array}$ & {$[59]$} \\
\hline $\begin{array}{l}\text { Indoor } \\
\text { environmental } \\
\text { quality analysis } \\
\end{array}$ & $\begin{array}{l}\text { Operation and } \\
\text { maintenance }\end{array}$ & $\begin{array}{l}\text { This work explores the application } \\
\text { of a real-time monitoring system }\end{array}$ & $\begin{array}{c}\text { Design a user-oriented } \\
\text { environmental control } \\
\text { model }\end{array}$ & $\begin{array}{l}\text { Rhino/Grasshopper, } \\
\text { Matlab }\end{array}$ & {$[60]$} \\
\hline $\begin{array}{l}\text { Fire evacuation } \\
\text { simulation }\end{array}$ & $\begin{array}{l}\text { Operation and } \\
\text { maintenance }\end{array}$ & $\begin{array}{c}\text { The study uses BIM to construct a } \\
\text { BIM-based intelligent fire } \\
\text { prevention and disaster relief } \\
\text { system. }\end{array}$ & $\begin{array}{c}\text { Design and } \\
\text { implementation of } \\
\text { proposed BIM-based fire } \\
\text { integrated system }\end{array}$ & Bluetooth, Revit & {$[50]$} \\
\hline
\end{tabular}

facility management (7D), and even n-D management models. For general building, BIM is still at the first level. However, BIM often tends to reach the second or even third level in smart buildings. Therefore, the elementary attributes of BIM need to be further integrated with other dimensions of time, cost, energy, and facilities to meet the higher requirements of smart buildings.

3.2. Lifecycles of Smart Buildings Based on BIM. Comparing to traditional buildings, smart buildings have a high level of technical content, risks, and complex construction procedures. Different domains or management approaches of the project can lead to different ways of dividing the project lifecycle (see Table 3). For example, Halfawy and Froese [62] divided the project lifecycle into three phases according to the project information flow process, from the design phase to the construction phase, to the facility management phase. Audier et al. [61] divided the project lifecycle into phases of design, construction, material supply, and operation according to the collaborative process
TABLe 3: Project lifecycle in existing research.

\begin{tabular}{lcccccccc}
\hline \multirow{8}{*}{ Project phases } & \multicolumn{10}{c}{ Review of research } \\
& [62] & [61] & [63] & [48] & [64] & [45] & [47] & [65] \\
\hline Planning & & & & $\checkmark$ & $\checkmark$ & $\checkmark$ & & $\checkmark$ \\
Design & $\checkmark$ & $\checkmark$ & & $\checkmark$ & $\checkmark$ & $\checkmark$ & $\checkmark$ & $\checkmark$ \\
Manufacture & & $\checkmark$ & $\checkmark$ & $\checkmark$ & & & & \\
Transportation & & $\checkmark$ & $\checkmark$ & $\checkmark$ & & & & \\
Construction & $\checkmark$ & $\checkmark$ & $\checkmark$ & $\checkmark$ & $\checkmark$ & & $\checkmark$ & $\checkmark$ \\
Operation & $\checkmark$ & $\checkmark$ & $\checkmark$ & $\checkmark$ & $\checkmark$ & $\checkmark$ & $\checkmark$ & $\checkmark$ \\
Maintenance & $\checkmark$ & & $\checkmark$ & $\checkmark$ & & $\checkmark$ & & $\checkmark$ \\
Refurbishment & & & $\checkmark$ & & & & & \\
Demolition & & & $\checkmark$ & & & & & \\
\hline
\end{tabular}

of project participants in the field of building materials. Yang et al. [63] proposed a BIM-based life cycle assessment method to promote the low-carbon design of buildings. The project lifecycle involved building materials production (including raw material extraction and manufacturing), material transportation, construction, operation, refurbishment, demolition, and waste disposal [63]. Li et al. [48] 
proposed that BIM is widely used in all phases of the lifecycle of prefabricated housing production projects, including feasibility study, design, manufacturing, transportation, construction, and maintenance. Forcael et al. [64] divided the project life cycle into the preinvestment phase, the investment phase, and the operation phase according to the investment process. The preinvestment phase included the generation and analysis of project ideas, feasibility study, and the preproject design; the investment phase contained design refinement and investment evaluation; the operation phase included bidding, construction, and maintenance [64].

The division of the smart buildings' lifecycle has also continued to emerge from research in recent years. For example, Marzouk and Othman [45] reviewed the research on the integration of BIM and GIS in urban development. The authors proposed that the research in this field mainly focused on the operation and maintenance phase, rarely involved the planning and design phase. Therefore, the role of BIM and GIS integration in the planning and design phase needs further exploration. Keskin and Salman [47] established a BIM implementation framework for smart airport life cycle management. The airport lifecycle was divided into design, construction, and operation [47]. Hetemi et al. [65] proposed that the coordination of different phases of BIM projects should be ensured in the case study, such as planning, design, construction, maintenance, and operation.

From the above research studies, the project of smart building starts with planning and design, followed by the manufacturing and transportation of materials. Then, the project reaches the construction phase. After the completion of the project, the project enters into the operation and maintenance phase. Finally, the refurbish and demolition of the building will occur after the use of the building for a long time. Due to the complexity of smart buildings (complex technology, many related links, and multiparty coordination), the planning and design of the early project phase must be considered. This paper does not explicitly study building materials but explores the overall situation of smart buildings. Considering that both manufacturing and transportation phases occur for building materials, this paper does not list the manufacturing and transportation phases separately. The main functions and return on investment by smart buildings are reflected in the project operation and maintenance phase, so the operation and maintenance phase must be included in the scope of full lifecycle management. The refurbish and demolition phase only needs to be considered after the smart building has been used for a long time. Moreover, the refurbish and demolition phase occupies a relatively small part of the full lifecycle of smart buildings and is similar to the reconstruction of another project, so it is no longer listed separately. Therefore, this paper divides the whole lifecycle of smart buildings into the planning and design phase, the construction phase, and the operation and maintenance phase.

3.2.1. Planning and Design Phase Based on BIM ( $\left.Y_{1}\right)$. Building intelligence has become an essential consideration in the planning and design of buildings. Traditional CAD technology design ability is limited and cannot meet the demand of current smart architecture, such as complex design, safety design, and multitechnology combined design. The $3 \mathrm{D}$ model provided by BIM can complete the complex design by extending the model, preventing design errors, and improving design efficiency. BIM can also be used for collision detection to enhance building safety. Moreover, BIM can be integrated with other technologies into the planning and design process to provide better plan projects understanding and compare different design solutions quickly and accurately.

First of all, the first step of the application of BIM technology is to create models. Singh et al. [66] elucidated the development of rule-based BIM objects that combine the design rules of the modular coordination (MC) standard with the application of BIM, allowing designers to create architectural models within the rules. Volkov and Batov [67] further proposed a dynamic extension of the BIM. The extended model may be of great use to developers of "smart" building solutions, designers who choose "smart" building solutions, facility managers, and developers of building codes and standards.

Secondly, risk management, such as collision detection and safety analysis, should be considered during the planning and design phase $\left(Y_{1}\right)$. To avoid reinforcement design errors or unsafe factors in design results, Liu et al. [68] conducted reinforcement collision detection with BIM technology to avoid reinforcement collision and blockage at beam-column joints. It is important to note that design changes during the design phase are inevitable. The impact of design changes in the construction project is omni-directional rather than partial, especially for the cost, schedule, and quality of the project. In this regard, Lin and Zhou [69] proposed a design change detection solution based on BIM technology, which is conducive to project design collaboration and quality control. Effective change detection based on BIM is achieved by matching two design versions of IDS and comparing all attributes in the BIM model. Porter et al. [55] analyzed the static and dynamic behaviors of the BIM surrounding environment by drawing a BIM entity map. The security analysis starts at the design phase of the project to further strengthen the security of the infrastructure. In the study of [70], the problem of productivity is also taken into account when considering safety issues. The researchers investigate the potential of BIM to improve the productivity $\left(Z_{2}\right)$ and safety performance of the construction industry. Specifically, BIM is used as a platform for risk management at the design phase $\left(Y_{1}\right)$, and a framework was developed for productivity and safety monitoring. The framework helps the project overcome problems caused by design defects and material selection errors, thus improving productivity and building safety.

Thirdly, the BIM platform can be integrated with other technologies $\left(Z_{4}\right)$ into the planning and design process, thus helping owners better plan projects and designers better complete design tasks. Marzouk and Othman [45] proposed a framework that integrates BIM and GIS to plan and forecast utility infrastructure needs. The proposed framework advocates carefully observing the stages of urban 
planning and development in order to form infrastructure requirements for a significant portion of performance during urban expansion and development. Ness et al. [71] discussed whether the combination of RFID technology and BIM could be used to track and import virtual models of components of a new building at the design stage.

3.2.2. Construction Phase Based on BIM ( $\left.Y_{2}\right)$. Smart construction is a part of smart buildings. BIM can simulate and visualize the construction process with a $3 \mathrm{D}$ geometric model and rich information to realize smart construction goals. Existing studies have proved that the application of BIM technology has strong practicality and economic benefits in the construction process $\left(Y_{2}\right)$, bringing new opportunities for more complex and smarter construction. The objectives of smart buildings during the construction phase $\left(Y_{2}\right)$ include schedule, cost, safety, quality, and environment. Figure 4 shows the five goals of smart construction based on BIM and the corresponding literature. Schedule and cost goals are closely related and often analyzed together in the literature. Safety is the most basic and essential goal in the construction phase. Quality and environmental goals are also important for smart buildings.

First, most BIM applications are designed for schedule and cost management $\left(Z_{2}\right)$ of construction projects. For example, Ma and Liu [72] established a method for automatic estimation of construction bidding costs based on BIM design results $\left(Z_{2}\right)$. The method focuses on the systematic identification and acquisition of construction information. For the construction cost estimation problem, Kim et al. [57] started from a highway project and built a smart 3D model based on the STEP (Standard for the Exchange of products) data model to predict the cost and duration of highway construction $\left(Z_{2}\right)$. Similarly, BIM-based cost and schedule management $\left(Z_{2}\right)$ has also been applied in the construction phase of bridge projects [56]. BIM technology applied for bridges is called bridge information modeling (BrIM), which has three submodules. The first module is the approximate estimation module. The module extracts the number of elements directly from BrIM and then multiplies the number with its corresponding unit price. The second module is the detailed estimation module. In addition to the number of elements extracted by BrIM, this module also considers productivity estimates, different material costs, and labor and equipment rates. The third module is the performance measurement module. This module can calculate the earned value using planned value and actual value and then determine budget and schedule status. The planned and actual values for each element can be extracted with Tekla Structures software or added manually by the user. Li et al. [73] also discussed the improvement of construction schedule through BIM technology-based digital management but focused on prefabricated buildings. Combining the IoT and BIM, the authors designed an Internet of Things platform to improve the daily operation efficiency and collaborative assembly capability of prefabricated components. Later, Li et al. [74] developed a realtime BIM platform involving various stakeholders, information flow, and the most advanced construction technologies to improve the construction schedule of prefabricated houses.

Secondly, BIM also has excellent potential to help improve the safety of smart building construction. For example, Riaz et al. [51] proposed a closed space environment monitoring scheme based on BIM and wireless sensor networks for the safety of construction personnel. The scheme can monitor temperature and oxygen levels in real time, thereby reducing the health and safety hazards for construction workers at the construction sites $\left(X_{4}\right)$. Other literature considers construction safety from the perspective of equipment management. Wang et al. [75] constructed the information model with the semiautomatic data integration method, covering the information requirements for solving the mathematical model of resource scheduling. This method strengthens the information transfer between BIM and the constrained mathematical model of resource scheduling $\left(X_{2}\right)$. Dutta et al. [52] used BIM to automatically replan the lifting path of tower cranes at the construction site $\left(Y_{2}\right)$ to provide the optimized lifting path without collision. The effective integration of equipment information and BIM solves the complex scheduling problem so as to promote the safety of equipment in the construction phase $\left(Y_{2}\right)$.

Thirdly, construction quality and environment are also essential aspects of smart buildings. The construction quality can be monitored with specific parameters data which are collected from the corresponding sensors and integrated into the BIM model. For example, Kim et al. [76] developed a dimension and surface quality assessment framework for precast concrete components with BIM and 3D laser scanning technology $\left(Z_{4}\right)$. The framework consists of four parts, including (1) the checklist, (2) the check program, (3) selecting the best scanner and scan parameters, and (4) storage and delivery methods of test data. What is more, construction environment analysis uses Revit to develop models and integrates them with other BIM energy-related tools (e.g., Green Building Design Studio) to simulate and analyze building performance $\left(Y_{1}\right)$. For example, Krasny et al. [77] analyzed and compared the impact and cost $\left(Z_{2}\right)$ of two different housing types on the environment through the energy analysis function of BIM and Baubook software.

\subsubsection{Operation and Maintenance Phase Based on BIM ( $\left.Y_{3}\right)$.} The operation and maintenance phase $\left(Y_{3}\right)$ takes a significant proportion in the whole building life cycle and involves more complex construction activities. Therefore, building performance in the operating phase is significant. The research studies in the operation and maintenance phase $\left(Y_{3}\right)$ are mainly divided into two aspects, including creating models for the existing building and serving operators and occupants.

Because of design changes and unintentional deviations, constructing a BIM model for a completed building to improve the building's smartness is more complicated than a new building. Xue et al. [78] proposed that constructing information models for built buildings is an ongoing challenge for the global BIM and computing engineering 


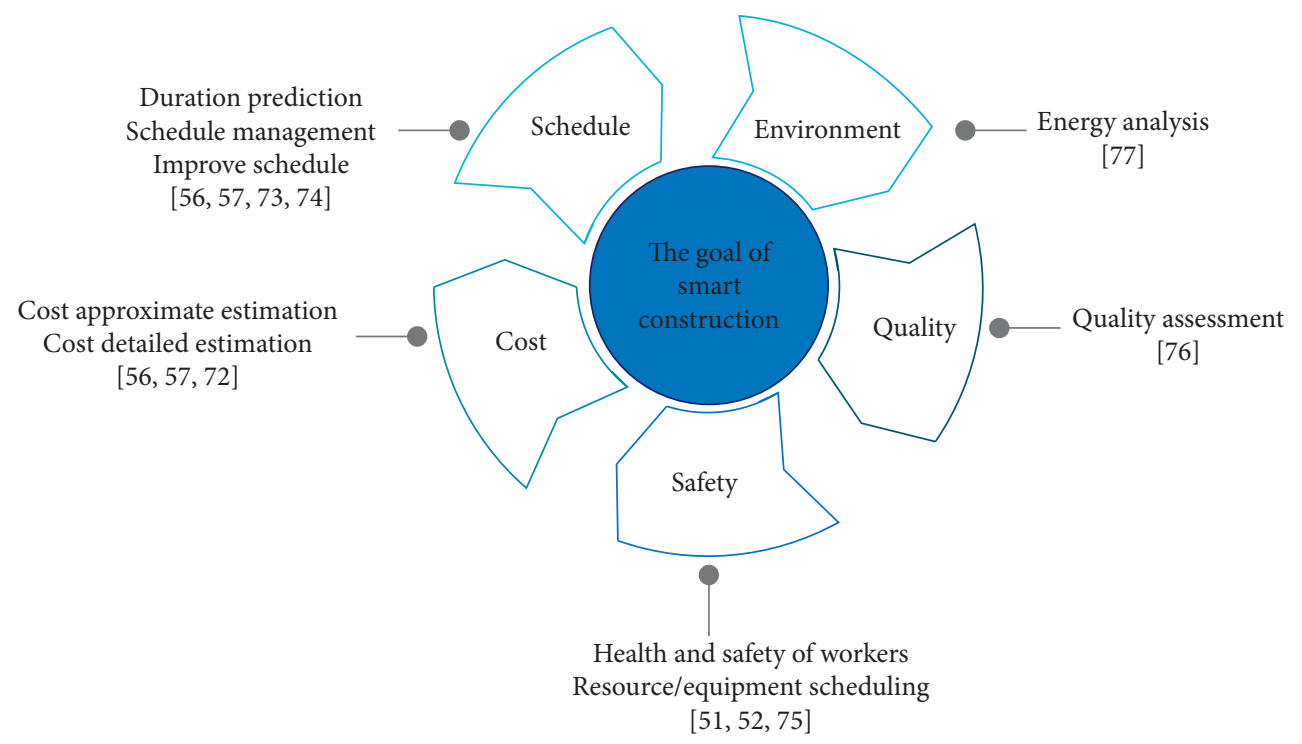

FIGURE 4: The goal of smart construction supported by BIM.

community. Chen et al. [79] proposed a method for automatically reconstructing the BIM model for the existing buildings based on multisource correction of geometric primitive (MSTEP). The method improves the level of building automation and reduces BIM construction time. Xue et al. [78] adopted 3D point clouds to generate rich semantics as-built BIMs automatically $\left(Z_{4}\right)$. The above method opens up a new way for BIM to be created from inexpensive data sources.

In the operation and maintenance phase $\left(Y_{3}\right)$, BIM serves designers and contractors as well as the operators and occupants. Keskin and Salman [47] proposed a comprehensive and adaptive airport BIM (ABIM) management framework for the operation and maintenance of the BIM platform. The framework helps airport operators access, manage, and utilize airport life cycle data on the BIM platform $\left(X_{2}\right)$, which achieves the digital management of airport projects and improves airport operational efficiency. Smart buildings are human-centered, so the experience of occupants is incredibly essential. Heidari et al. [59] proposed a BIM-based smart design system to simulate the daily activities of users, improving the communication between users and designers in the process of smart environmental design $\left(Z_{3}\right)$. Smart BIM is used to create virtual space containing smart objects that can perform certain functions and react to user interactions based on the set of attributes of the objects. Rashid et al. [80] also provides users with a smart indoor environment $\left(Z_{3}\right)$ but does not consider the interaction between users and smart objects. This research mainly used indoor location tracking and a BIM-based virtual environment to realize equipment control of smart buildings. To improve the experience of residents, Habibi [60] focused on providing users with the best indoor environmental quality (IEQ) $\left(Z_{3}\right)$. The study explored a realtime monitoring system and created a BIM model of the existing campus buildings in case analysis, thus evaluating the indicators of building energy consumption and indoor comfort $\left(Z_{1}, Z_{3}\right)$. BIM applications connect users with the building system closely in the operation and maintenance phase to improve building energy efficiency and user comfort $\left(Z_{3}\right)$, which is in line with the primary content of smart buildings.

3.2.4. Summary of the Project Phases Based on BIM. In general, the advantages of using BIM in the life cycle of smart buildings have two aspects. On the one hand, BIM provides $3 \mathrm{D}$ visual models $\left(X_{3}\right)$ to realize information sharing and exchange $\left(X_{2}\right)$. Therefore, BIM can facilitate the data exchange of different disciplines' tools and the collaboration of different stakeholders. On the other hand, BIM can be integrated with other tools $\left(Z_{4}\right)$ to solve specific architectural problems by analyzing and simulating building performance $\left(X_{4}\right)$. Thus, BIM is beneficial for controlling project cost, schedule, and environmental pollution effectively and promoting smart construction. Existing articles show that BIM provides a rich information model to solve problems related to the entire life cycle of smart buildings (see Table 4). Table 4 shows that the types of smart buildings supported by BIM are mainly office and residential buildings, with a small number of applications in bridges, highways, airports, and other transportation infrastructure.

3.3. Functions of Smart Buildings Based on BIM. With people's yearning for intelligent life and work, there is an urgent need to adopt more advanced technology to realize the smart functions of buildings in recent years. Thus, the functions of smart buildings are continuously developed and improved [82]. The core driving force for the continuous development of smart buildings includes four aspects: reduced energy consumption $\left(Z_{1}\right)$, increased economic efficiency $\left(Z_{2}\right)$, improved life quality of users $\left(Z_{3}\right)$, and integration with other technologies $\left(Z_{4}\right)$ (see Figure 5) [42]. In order to further promote the development of smart buildings, BIM has been widely studied to provide smart building solutions. This section provides a review of current BIM applications in the field of smart buildings from the above four aspects. 
TABLE 4: Review cases of BIM-based smart buildings in the building life cycle.

\begin{tabular}{|c|c|c|c|c|c|}
\hline Project phases & Building types & Application areas & Country/regions & BIM tools & References \\
\hline \multirow{3}{*}{$\begin{array}{l}\text { Planning and } \\
\text { design phase }\end{array}$} & $\begin{array}{l}\text { A two-story RC building } \\
\text { frame }\end{array}$ & $\begin{array}{l}\text { Automated clash resolution } \\
\text { for reinforcement steel } \\
\text { design }\end{array}$ & Not defined & $\begin{array}{c}\text { Autodesk Revit, } \\
\text { PKPM }\end{array}$ & {$[68,81]$} \\
\hline & $\begin{array}{l}\text { Residential/commercial/ } \\
\text { administrative/industrial } \\
\text { housing }\end{array}$ & $\begin{array}{l}\text { Planning utility } \\
\text { infrastructure } \\
\text { requirements }\end{array}$ & New Cairo, Egypt & Not defined & {$[45]$} \\
\hline & $\begin{array}{l}\text { The demolition/ } \\
\text { deconstruction of a former } \\
\text { industrial building }\end{array}$ & The reuse of steel & $\begin{array}{c}\text { Southern Adelaide, } \\
\text { Australia }\end{array}$ & Not defined & {$[71]$} \\
\hline \multirow{7}{*}{$\begin{array}{l}\text { Construction } \\
\text { phase }\end{array}$} & Highway construction & Cost/schedule estimates & Seoul, Korea & Revit, SketchUp & {$[57]$} \\
\hline & Bridge & Cost and time management & $\begin{array}{c}\text { Al-Buhayrah Governorate, } \\
\text { Egypt }\end{array}$ & Tekla Structures & {$[56]$} \\
\hline & $\begin{array}{l}\text { Strawbale house and } \\
\text { concrete/brick homes }\end{array}$ & $\begin{array}{c}\text { Energy analysis and } \\
\text { construction cost } \\
\text { calculation }\end{array}$ & Bosnia and Herzegovina & $\begin{array}{l}\text { Revit, Green } \\
\text { Building Design } \\
\text { Studio }\end{array}$ & {$[77]$} \\
\hline & Precast concretes & $\begin{array}{c}\text { Dimensional and surface } \\
\text { quality assessment }\end{array}$ & Not defined & Not defined & {$[76]$} \\
\hline & Residential construction & $\begin{array}{l}\text { On-site assembly services } \\
\text { in prefabricated } \\
\text { construction }\end{array}$ & Hong Kong, China & Revit & {$[73]$} \\
\hline & Apartment & $\begin{array}{l}\text { Resource-constrained } \\
\text { scheduling }\end{array}$ & Hefei, China & Revit & {$[75]$} \\
\hline & Residential block & $\begin{array}{l}\text { Automatic replanning of } \\
\text { lifting paths for robotized } \\
\text { tower cranes }\end{array}$ & Singapore & Not defined & {$[52]$} \\
\hline \multirow{7}{*}{$\begin{array}{l}\text { Operation and } \\
\text { maintenance } \\
\text { phase }\end{array}$} & Auditorium & $\begin{array}{c}\text { Automatic generation of } \\
\text { semantically rich as-built } \\
\text { BIM }\end{array}$ & Not defined & Revit & {$[78]$} \\
\hline & $\begin{array}{l}1361 \text { blocks of densely } \\
\text { distributed buildings }\end{array}$ & $\begin{array}{l}\text { Automatic building } \\
\text { information model } \\
\text { reconstruction }\end{array}$ & Hong Kong, China & Not defined & {$[79]$} \\
\hline & Airport & $\begin{array}{l}\text { Enhance operational } \\
\text { efficiencies through the } \\
\text { ABIM framework }\end{array}$ & $\begin{array}{c}\text { Asia Pacific, Europe, } \\
\text { Middle East, South } \\
\text { America, and North } \\
\text { America }\end{array}$ & Not defined & {$[47]$} \\
\hline & Smart home objects & $\begin{array}{l}\text { Help end-users to } \\
\text { experience daily activity in } \\
\text { a virtual environment }\end{array}$ & Not defined & Not defined & {$[59]$} \\
\hline & Office buildings & $\begin{array}{l}\text { Improve indoor } \\
\text { environmental quality } \\
\text { (IEQ) and energy efficiency }\end{array}$ & Barcelona, Spain & $\begin{array}{l}\text { Revit, Ecotect, } \\
\text { Rhino/ } \\
\text { Grasshopper }\end{array}$ & {$[60]$} \\
\hline & $\begin{array}{c}\text { Multipurpose twelve-story } \\
\text { building }\end{array}$ & $\begin{array}{l}\text { Building fire prevention } \\
\text { and disaster relief }\end{array}$ & Northern Taiwan & Revit & {$[50]$} \\
\hline & Office room & $\begin{array}{l}\text { Wireless electric appliance } \\
\text { control }\end{array}$ & Oregon State, America & Not defined & {$[80]$} \\
\hline
\end{tabular}

3.3.1. Reducing Energy Consumption $\left(Z_{1}\right)$. The rapid development of information technology promotes the development of smart buildings. Excessive energy consumption leads to environmental deterioration, which promotes the development of smart buildings to some extent. Buildings consume approximately one-third of the world's resources, resulting in a large amount of energy consumption and excessive construction waste [83]. Excessive use of construction resources has led to various environmental problems that urgently need to be solved. The realization of smart functions of smart buildings depends on the management and control of energy in the whole life cycle of buildings [84]. BIM can be applied to the energy detection and energy consumption management of smart buildings, thus improving the resource efficiency of the project by preventing excessive waste [85] $\left(Z_{1}\right)$. Based on building energy consumption data, BIM can also design and evaluate buildings' full life cycle to mitigate the negative environmental impact of construction projects [83] $\left(Z_{1}\right)$.

The energy management of BIM-based smart buildings has been widely studied. Part of the literature on BIM-based energy management focuses on the monitoring of building energy. For example, Gökçe and Gökçe [86] compare data extracted from BIM and other tools which use dynamic data to support decision-making, promoting building energyspecific monitoring and management capabilities $\left(Z_{1}\right)$. 


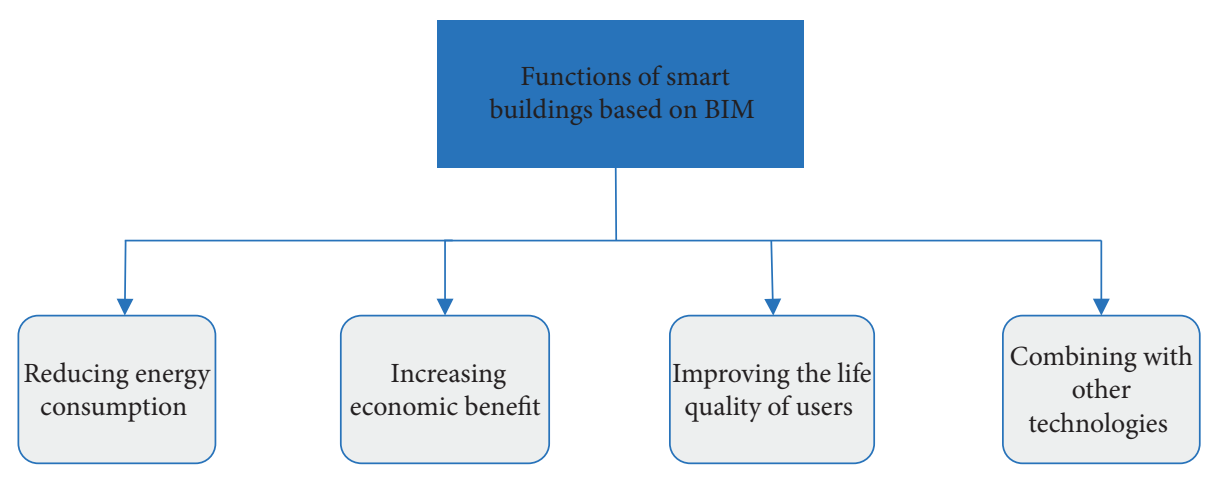

FIGURE 5: Smart building functions based on BIM.

Besides, McGlinn et al. [87] used BIM and semantic web technologies to integrate buildings, sensors, driving infrastructure, and smart software components $\left(Z_{4}\right)$. Recommendations based on data measured by indoor sensors are generated for facility managers to alert potential energysaving actions. There are also two papers on energy management from different perspectives, mainly focusing on building energy consumption management. Kaewunruen et al. [88] used Revit and Insight software to construct energy and cost analysis models of existing buildings to determine the efficiency of building energy consumption $\left(Z_{1}\right)$. Kang and Choi [89] combined the rich building information in BIM with the data acquisition framework to propose an effective building energy management decision method $\left(Z_{1}\right)$. The method helps managers realize the comprehensive utilization of space and energy management data and effectively manage building energy.

BIM can also be used for building environmental performance assessment and analysis $\left(Z_{1}\right)$. Yang et al. [63] proposed a life cycle assessment (LCA) method based on BIM technology from the perspective of the full life cycle of buildings. The method used BIM tools to create BIM models and analyze relevant data required for LCA [63]. The data cover building materials, construction machinery, energy, and water. Design builder software (based on EnergyPlus) is used to identify and quantify energy consumption at each phase to assess the building's whole life cycle environmental performance. Zhang et al. [90] mainly conducted a real-time evaluation of green buildings on the design phase $\left(Y_{1}\right)$ without considering the entire building life cycle. BIM in this approach is mainly used to provide a collaborative environment for connecting all project stakeholders, promoting information exchange in the green building rating process $\left(X_{2}\right)$. Jiang et al. [91] also discussed the green building evaluation method. In the new green building evaluation method with BIM and ontology proposed in this paper, BIM is considered as the database to provide the convenient acquisition of required information in the green building evaluation $\left(X_{2}\right)$. The above methodological contributions have far-reaching value in reducing the energy consumption of smart buildings.

3.3.2. Increasing Economic Benefits $\left(Z_{2}\right)$. The rapid development of smart buildings is inseparable from the great demand for materials, equipment, and technical personnel, which also causes an increase in construction costs. Managers can use the BIM model to calculate the material quantity and cost, thereby reducing project costs and resource waste and improving the economic benefits of projects and enterprises $\left(Z_{2}\right)$. Marzouk and Hisham [56] used BIM technology to estimate the approximate cost and the detailed cost of bridge projects. Kim et al. [57] determined the earthwork quantity, cost, and construction schedule by creating a three-dimensional model of the expressway and helped the design team estimate the total project cost.

Unpredictable changes may occur in building smart buildings, and BIM model data will also need to be changed accordingly. Changing data require managers to make adjustments quickly to improve economic benefits as much as possible. For instance, Lu and Olofsson [92] proposed an integrated framework of BIM and discrete event simulation (DES). The framework included a building information modeling process and a smart simulation engine [92]. The building information modeling application requires exporting the material quantity, operation schedules, and resources needed to a relational database. The smart simulation engine automatically reads the information from the database to understand the building information changes in real time. The framework can discover the uncertainties in construction operations quickly and explore alternative solutions to improve project performance and avoid losses. Similarly, Lin et al. [93] proposed a natural-language-based cloud BIM approach to support data retrieval and representation $\left(Z_{4}\right)$. Cloud BIM enhances the value of BIM big data and promotes the application of BIM in enterprises, thus increasing the economic benefits of enterprises. It should be noted that the adoption of BIM technology will definitely increase the cost of smart buildings; thus, only effective application of this technology can produce benefits. As a result, high costs and unclear profitability make many projects cautious about adopting BIM.

3.3.3. Improving the Life Quality of Users $\left(Z_{3}\right)$. People orientation is the core concept of smart buildings, so the user experience is very crucial. BIM technology is conducive to the interaction between users and smart objects, which 
realize the rapid response to user needs. BIM technology can also help solve emergencies in smart buildings and ensure the safety of users.

Smart buildings need to respond to the changing needs of users quickly and implement specific functions such as building control, automation, and security [94]. For instance, Rashid et al. [80] integrated IoT infrastructure and BIM-based virtual environment $\left(Z_{4}\right)$ to enable users to control electrical appliances in the smart home environment and provide users with a convenient, comfortable, and energy-saving environment $\left(Z_{3}\right)$. The integration of the indoor positioning system and the inertial measurement unit (IMU) can achieve user information retrieval and environmental information collecting. The BIM-based virtual environment turns on or off the IoT infrastructure in the building according to the receiving information. In another study, Habibi [95] used BIM and smart sensors to create a smart building energy real-time management system to improve indoor environmental quality (IEQ) and user comfort $\left(Z_{3}\right)$.

In terms of improving security and disaster response capability, BIM technology simulates the disaster occurrence $\left(X_{4}\right)$ before the disaster and updates emergency information for effective emergency response inside the building after the disaster. For example, Cheng et al. [50] constructed BIMbased smart fire prevention and disaster mitigation system to strengthen fire rescue and fire hazard control. The system can show users a 3D site $\left(X_{3}\right)$ and help them understand fire or other emergencies immediately. Porter et al. [55] also discussed user safety and disaster response, emphasizing safety fire hazard warning. This study conducted static and dynamic security analysis with BIM to check the potential security risks of facilities and ensure users' safety $\left(Z_{3}\right)$.

3.3.4. Combining with Other Technologies $\left(Z_{4}\right)$. The successful implementation of smart building projects is inseparable from the combination of BIM technology and other advanced information technologies. The integration of BIM and other advanced technologies provides more possibilities for the applications of BIM. The emergence of technology integration schemes, such as BIM + GIS, $\mathrm{BIM}+\mathrm{IOT}$, and BIM + cloud computing, has gradually formed the concept of "BIM+" and promoted the further applications of BIM in the field of construction (see Figure 6).

First, the integration of BIM and GIS has become an important direction of the construction industry with the continuous development and popularization of BIM and GIS in smart buildings. GIS focuses on applying geospatial information, while BIM focuses on the detailed information inside the building. The combination of the two technologies provides the whole data foundation of indoor and outdoor, which is also the spatial data foundation of smart buildings. For example, Yamamura et al. [96] proposed a GIS-BIMbased urban energy planning system $\left(Z_{4}\right)$. The system can integrate GIS-based data with other data sources from cities, communities, and buildings to integrate urban models, predict and simulate the effects of energy-saving

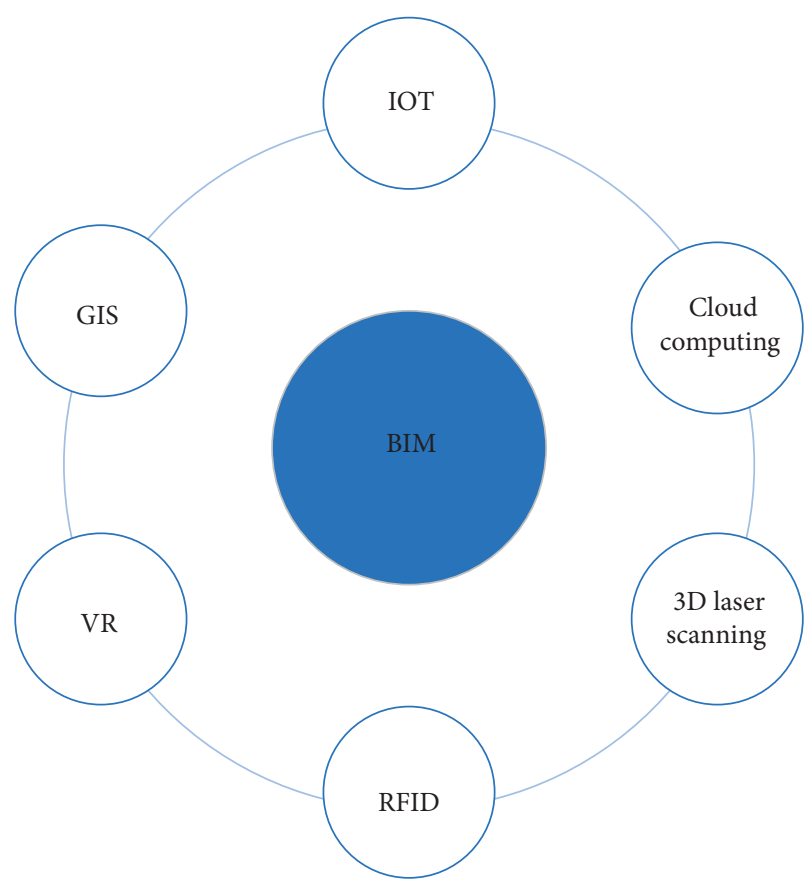

FIGURE 6: Integration diagram of BIM and other advanced technologies.

technologies, and visualize 3D urban modeling. The framework proposed in [45] is also based on BIM and GIS technologies $\left(Z_{4}\right)$, but with different uses. This study's primary purpose is to plan and predict the utility requirements for urban expansion $\left(Y_{1}\right)$.

Second, the core of BIM and IoT integration is integrating data from different systems in the whole life cycle of smart buildings. IoT capabilities enable the continuous flow of real-time data to yield significant benefits from integration with BIM models. Real-time data collected from the IoT can be assigned to the digital entities in the BIM model to represent a wide range of valuable information [85]. For example, Dave et al. [97] developed a BIM and IoT-based platform that provides information about energy consumption and user comfort $\left(X_{2}, Z_{4}\right)$. Another application of BIM and IoT integration $\left(Z_{4}\right)$ is proposed for smart home control [80]. However, research studies on BIM and IoT integration are still in the early stage. Tang et al. [98] collated the relevant literature of the last decade and analyzed these articles in terms of construction operations monitoring, human resource management, and construction logistics management. Potential research directions in this area are suggested to include creating service-oriented architecture (SOA) models and web services for BIM and IoT integration, establishing standards for information integration and management, addressing interoperability issues, and cloud computing.

Third, the integration of BIM and cloud computing also injects new impetus into smart buildings. Combining powerful computing capabilities of cloud computing with the visualization capabilities of BIM, the computationally intensive and complex tasks in BIM applications can be transferred to the cloud to improve operating efficiency. For 
example, Lin et al. [93] proposed that BIM can automatically retrieve user-related data based on cloud computing and form visual maps and comprehensive reports, thereby enhancing the BIM application value and promoting the BIM technology application in smart buildings $\left(X_{3}, Z_{4}\right)$.

Fourth, BIM can also be integrated with radio frequency identification (RFID) technology to achieve more smart functions. RFID technology can identify specific targets and read relevant data, whereas BIM can effectively conduct information management. RFID is combined with BIM and applied to different scenes from different research perspectives, including tracking smart building components and equipment detection in real time. For example, Ness et al. [71] combined RFID and BIM $\left(Z_{4}\right)$ to track the components of a new building and import data into the model to achieve the recovery and utilization of components. Tsai et al. [99] integrated RFID data collection into the BIM system $\left(Z_{4}\right)$ to inspect the material corrosion on the construction site $\left(Y_{2}\right)$. Li et al. [74] developed a BIM platform based on RFID technology $\left(Z_{4}\right)$ to deal with crucial schedule factors, promoting collaborative work between smart building objects and RFID. The platform improves the success rate of the daily operation and decision-making in prefabricated construction project management and ensures timely delivery of projects.

Fifth, BIM can be further combined with surveying and mapping technology to promote the overall development of smart buildings. For example, Kim et al. [76] proposed a quality assurance system for precast concrete based on BIM and $3 \mathrm{D}$ laser scanning technology $\left(Z_{4}\right)$. The system used a laser scanner to scan precast concrete units placed in predetermined positions [76]. Then the system checks the component list, confirms the parameters, and evaluates the results in the detection and data management modules so that the system can be effectively interoperable with BIM [76].

BIM can be integrated with multiple advanced information technologies to achieve more BIM functions and higher-level smart buildings. For example, Li et al. [73] designed an IoT platform to provide decision-making and monitoring services for different stakeholders. To be specific, real-time data are collected at the construction site using RFID technology and then uploaded to the cloud for processing and analysis to provide decision support for on-site staff. Besides, BIM and virtual reality (VR) technologies are used to develop visibility and traceability functions. Moreover, it is convenient for managers to monitor construction progress and cost information in real time [73]. In summary, the deep integration of BIM and other advanced information technologies will promote the rapid development of smart buildings, thus expanding the smart building applications. However, BIM and other advanced information technologies are still in the preliminary development phase and have extensive prospects and development potential.

\subsection{Cross-Analysis of the Nexus of BIM and Smart Buildings.} The cross-analysis of the nexus of BIM and smart buildings means analyzing the application considering all dimensions of nexus, including BIM attributes $(X)$, project phases $(Y)$, and smart attributes $(Z)$. As presented in Sections 3.1-3.3, the analysis of each dimension must involve analyzing other dimensions. Therefore, three dimensions must be combined to achieve the comprehensive understanding and guidance of smart building based on BIM technology. Table 5 shows the application cases of cross-analysis in $X, Y$, and $Z$ dimensions. Figure 7 shows the results of the cross-analysis of three dimensions. BIM is used widely in smart buildings, such as facility planning, energy simulation, and safety analysis. Different intersections among the $X, Y$, and $Z$ axes represent different applications (see Figure 7). The applications are as follows.

\subsubsection{Automatic Evaluation of Machine Capability.} During off-site construction $\left(Y_{2}\right)$, applying the BIM's integrating properties with other systems, the BIM and manufacturing system are integrated $\left(X_{1}\right)$ to form a framework for automatically evaluating machine capabilities [44]. The framework has the potential to effectively improve the productivity, quality, and deliverability of products, thereby realizing the smartness in improving economic benefits $\left(Z_{2}\right)$. The automatic evaluation of machine capability based on BIM improves the production efficiency and quality of construction products in the manufacturing stage.

\subsubsection{Operational Efficiency Improvement. By connecting} existing data sources and operating systems, BIM-based processes are used in smart buildings' operation and maintenance $\left(Y_{3}\right)$ for the facility manager to access, manage, and utilize operational data in a digital collaborative environment $\left(X_{2}\right)$ [47]. The airport BIM (ABIM) framework helps airport operators use airport life cycle data on the BIM platform to coordinate the engineering aspects of airport management throughout the whole lifecycle [47]. Thus, the BIM-based operation process guides stakeholders to realize digital operation management and improve operational efficiency $\left(Z_{2}\right)$. Improved operational efficiency of smart buildings will help reduce operating costs and increase project revenue.

3.4.3. Fire Prevention. Fire prevention is an important emergency event that needs to be considered during the operation and maintenance phase of smart buildings $\left(Y_{3}\right)$. When the sensor detects a sufficiently high temperature or smoke level, the 3D model supported by BIM can be used to monitor the location of the fire outbreak and visualizing the evacuation and rescue route $\left(X_{3}\right)$ [50]. Real-time dynamic evacuation guidance is automatically provided on user equipment through BIM software to improve the fire control and rescue, thus ensuring user safety $\left(Z_{3}\right)$. The fire protection application based on BIM technology improves disaster response capabilities and effectively improves the building security and safety management level.

3.4.4. Protecting the Safety of Constructors. The updated building information from the sensor data (oxygen concentration, temperature, etc.) can be stored in the Revit software to facilitate information acquisition and sharing 
TABLE 5: Interaction of BIM attributes $(X)$, project phases $(Y)$, and smart attributes $(Z)$.

\begin{tabular}{|c|c|c|c|c|c|c|c|}
\hline Applications & $\begin{array}{c}X: \text { BIM } \\
\text { attributes }\end{array}$ & Description of $X$ & $\begin{array}{c}Y: \text { project } \\
\text { phases }\end{array}$ & $\begin{array}{l}Z \text { : smart } \\
\text { attributes }\end{array}$ & Description of $Z$ & $\begin{array}{c}\text { Corresponding } \\
\text { section }\end{array}$ & Ref. \\
\hline $\begin{array}{l}\text { Automatic } \\
\text { evaluation of } \\
\text { machine } \\
\text { capability }\end{array}$ & $\begin{array}{l}X_{1} \text { : integration } \\
\text { with other } \\
\text { systems }\end{array}$ & $\begin{array}{c}\text { Integrated BIM } \\
\text { and } \\
\text { manufacturing } \\
\text { systems }\end{array}$ & $\begin{array}{c}Y_{2}: \text { construction } \\
\text { phase based on } \\
\text { BIM }\end{array}$ & $\begin{array}{c}Z_{2}: \text { increasing } \\
\text { economic } \\
\text { benefits }\end{array}$ & $\begin{array}{l}\text { Increase the } \\
\text { productivity, } \\
\text { quality, and } \\
\text { deliverability of } \\
\text { the products }\end{array}$ & 3.1 .1 & {$[44]$} \\
\hline $\begin{array}{l}\text { Operational } \\
\text { efficiency } \\
\text { improvement }\end{array}$ & $\begin{array}{c}X_{2}: \\
\text { convenience } \\
\text { of information } \\
\text { sharing and } \\
\text { exchange }\end{array}$ & $\begin{array}{l}\text { Access, manage, } \\
\text { and utilize } \\
\text { airport life cycle } \\
\text { data on the BIM } \\
\text { platform }\end{array}$ & $\begin{array}{l}Y_{3}: \text { operation } \\
\text { and } \\
\text { refurbishment } \\
\text { phase based on } \\
\text { BIM }\end{array}$ & $\begin{array}{l}Z_{2}: \text { increasing } \\
\text { economic } \\
\text { benefits }\end{array}$ & $\begin{array}{l}\text { Achieve digital } \\
\text { management }\end{array}$ & 3.2 .3 & {$[47]$} \\
\hline Fire prevention & $\begin{array}{c}X_{3}: \\
\text { visualization } \\
\text { of whole } \\
\text { process and } \\
\text { results }\end{array}$ & $\begin{array}{l}\text { Visualize the fire } \\
\text { situation }\end{array}$ & $\begin{array}{l}Y_{3}: \text { operation } \\
\text { and } \\
\text { refurbishment } \\
\text { phase based on } \\
\text { BIM }\end{array}$ & $\begin{array}{c}Z_{3} \text { : improving } \\
\text { the life quality } \\
\text { of users }\end{array}$ & $\begin{array}{l}\text { Strengthen fire } \\
\text { rescue and users' } \\
\text { safety }\end{array}$ & $\begin{array}{l}3.1 .3 \\
3.3 .3\end{array}$ & {$[50]$} \\
\hline $\begin{array}{l}\text { Protecting the } \\
\text { safety of } \\
\text { constructors }\end{array}$ & $\begin{array}{c}X_{2}: \\
\text { convenience } \\
\text { of information } \\
\text { sharing and } \\
\text { exchange }\end{array}$ & $\begin{array}{c}\text { The latest sensor } \\
\text { data stored in } \\
\text { Revit }\end{array}$ & $\begin{array}{c}Y_{2}: \text { construction } \\
\text { phase based on } \\
\text { BIM }\end{array}$ & $\begin{array}{c}Z_{4} \text { : } \\
\text { combining } \\
\text { with other } \\
\text { technologies }\end{array}$ & $\begin{array}{l}\text { Combine BIM } \\
\text { and wireless } \\
\text { sensor network } \\
\text { (WSN)/IoT }\end{array}$ & $\begin{array}{l}3.1 .3 \\
3.3 .4\end{array}$ & {$[51,73]$} \\
\hline $\begin{array}{l}\text { Equipment } \\
\text { scheduling }\end{array}$ & $\begin{array}{c}X_{3}: \\
\text { visualization } \\
\text { of whole } \\
\text { process and } \\
\text { results }\end{array}$ & $\begin{array}{c}\text { Visual } \\
\text { construction site }\end{array}$ & $\begin{array}{l}Y_{2}: \text { construction } \\
\text { phase based on } \\
\text { BIM }\end{array}$ & $\begin{array}{c}Z_{4} \text { : } \\
\text { combining } \\
\text { with other } \\
\text { technologies }\end{array}$ & $\begin{array}{c}\text { Integrate RFID } \\
\text { data collection } \\
\text { into the BIM } \\
\text { system }\end{array}$ & $\begin{array}{l}3.2 .2 \\
3.3 .4\end{array}$ & {$[52,99]$} \\
\hline Safety analysis & $\begin{array}{c}X_{4} \text { : analysis } \\
\text { and } \\
\text { simulation of } \\
\text { building } \\
\text { functions }\end{array}$ & $\begin{array}{c}\text { Static and } \\
\text { dynamic security } \\
\text { analysis }\end{array}$ & $\begin{array}{c}Y_{1} \text { : planning } \\
\text { and design } \\
\text { phase based on } \\
\text { BIM }\end{array}$ & $\begin{array}{c}Z_{3} \text { : improving } \\
\text { the life quality } \\
\text { of users }\end{array}$ & $\begin{array}{c}\text { Improve building } \\
\text { safety }\end{array}$ & $\begin{array}{l}3.1 .4 \\
3.2 .1 \\
3.3 .3\end{array}$ & {$[55,58,70]$} \\
\hline Cost estimation & $\begin{array}{c}X_{4} \text { : analysis } \\
\text { and } \\
\text { simulation of } \\
\text { building } \\
\text { functions }\end{array}$ & Estimate the cost & $\begin{array}{c}Y_{2}: \text { construction } \\
\text { phase based on } \\
\text { BIM }\end{array}$ & $\begin{array}{c}Z_{2} \text { : increasing } \\
\text { economic } \\
\text { benefits }\end{array}$ & $\begin{array}{c}\text { Cost } \\
\text { management }\end{array}$ & $\begin{array}{l}3.1 .4 \\
3.2 .2 \\
3.3 .2\end{array}$ & {$[56,57,72]$} \\
\hline $\begin{array}{l}\text { Schedule } \\
\text { estimation }\end{array}$ & $\begin{array}{c}X_{4} \text { : analysis } \\
\text { and } \\
\text { simulation of } \\
\text { building } \\
\text { functions }\end{array}$ & $\begin{array}{l}\text { Estimate the } \\
\text { construction } \\
\text { duration }\end{array}$ & $\begin{array}{l}Y_{2}: \text { construction } \\
\text { phase based on } \\
\text { BIM }\end{array}$ & $\begin{array}{c}Z_{2}: \text { increasing } \\
\text { economic } \\
\text { benefits }\end{array}$ & $\begin{array}{c}\text { Schedule } \\
\text { management }\end{array}$ & $\begin{array}{l}3.1 .4 \\
3.2 .2 \\
3.3 .2 \\
3.3 .4\end{array}$ & {$[56,57,74]$} \\
\hline $\begin{array}{l}\text { Energy } \\
\text { performance } \\
\text { simulation }\end{array}$ & $\begin{array}{c}X_{4} \text { : analysis } \\
\text { and } \\
\text { simulation of } \\
\text { building } \\
\text { functions }\end{array}$ & $\begin{array}{c}\text { Simulation } \\
\text { energy } \\
\text { performance data }\end{array}$ & $\begin{array}{l}Y_{3}: \text { operation } \\
\text { and } \\
\text { refurbishment } \\
\text { phase based on } \\
\text { BIM }\end{array}$ & $\begin{array}{l}Z_{1}: \text { reducing } \\
\text { energy } \\
\text { consumption }\end{array}$ & $\begin{array}{c}\text { Promote building } \\
\text { energy-specific } \\
\text { monitoring and } \\
\text { management } \\
\text { capabilities }\end{array}$ & $\begin{array}{l}3.1 .4 \\
3.3 .1\end{array}$ & {$[43,54,86]$} \\
\hline $\begin{array}{l}\text { Indoor } \\
\text { equipment } \\
\text { control }\end{array}$ & $\begin{array}{l}X_{4} \text { : analysis } \\
\text { and } \\
\text { simulation of } \\
\text { building } \\
\text { functions }\end{array}$ & $\begin{array}{c}\text { Simulate the } \\
\text { daily activities of } \\
\text { users }\end{array}$ & $\begin{array}{c}Y_{3} \text { : operation } \\
\text { and } \\
\text { refurbishment } \\
\text { phase based on } \\
\text { BIM }\end{array}$ & $\begin{array}{c}Z_{3} \text { : improving } \\
\text { the life quality } \\
\text { of users }\end{array}$ & $\begin{array}{l}\text { Help end-users } \\
\text { to experience } \\
\text { their daily } \\
\text { activity in a } \\
\text { virtual } \\
\text { environment }\end{array}$ & $\begin{array}{l}3.1 .4 \\
3.3 .3\end{array}$ & {$[59,80]$} \\
\hline $\begin{array}{l}\text { Indoor } \\
\text { environmental } \\
\text { quality analysis }\end{array}$ & $\begin{array}{c}X_{4} \text { : analysis } \\
\text { and } \\
\text { simulation of } \\
\text { building } \\
\text { functions }\end{array}$ & $\begin{array}{c}\text { Energy real-time } \\
\text { analysis }\end{array}$ & $\begin{array}{l}Y_{3}: \text { operation } \\
\text { and } \\
\text { refurbishment } \\
\text { phase based on } \\
\text { BIM }\end{array}$ & $\begin{array}{c}Z_{3} \text { : improving } \\
\text { the life quality } \\
\text { of users }\end{array}$ & $\begin{array}{l}\text { Provide users } \\
\text { with the best } \\
\text { indoor } \\
\text { environmental } \\
\text { quality (IEQ) }\end{array}$ & $\begin{array}{l}3.1 .4 \\
3.3 .3\end{array}$ & {$[60,95]$} \\
\hline
\end{tabular}


TABle 5: Continued.

\begin{tabular}{|c|c|c|c|c|c|c|c|}
\hline Applications & $\begin{array}{c}X: \text { BIM } \\
\text { attributes }\end{array}$ & Description of $X$ & $\begin{array}{l}Y: \text { project } \\
\text { phases }\end{array}$ & $\begin{array}{l}Z: \text { smart } \\
\text { attributes }\end{array}$ & Description of $Z$ & $\begin{array}{c}\text { Corresponding } \\
\text { section }\end{array}$ & Ref. \\
\hline $\begin{array}{l}\text { Recovery and } \\
\text { utilization of } \\
\text { components }\end{array}$ & $\begin{array}{c}X_{2}: \\
\text { convenience } \\
\text { of information } \\
\text { sharing and } \\
\text { exchange }\end{array}$ & $\begin{array}{l}\text { Track and locate } \\
\text { all the elements } \\
\text { that make up the } \\
\text { actual building }\end{array}$ & $\begin{array}{c}Y_{1} \text { : planning } \\
\text { and design } \\
\text { phase based on } \\
\text { BIM }\end{array}$ & $\begin{array}{c}Z_{4} \text { : } \\
\text { combining } \\
\text { with other } \\
\text { technologies }\end{array}$ & $\begin{array}{l}\text { Combine BIM } \\
\text { and RFID }\end{array}$ & $\begin{array}{l}3.2 .1 \\
3.3 .4\end{array}$ & {$[71]$} \\
\hline $\begin{array}{l}\text { Quality } \\
\text { assessment }\end{array}$ & $\begin{array}{c}X_{2}: \\
\text { convenience } \\
\text { of information } \\
\text { sharing and } \\
\text { exchange }\end{array}$ & $\begin{array}{l}\text { Store and recall } \\
\text { information } \\
\text { about a facility }\end{array}$ & $\begin{array}{c}Y_{2}: \text { construction } \\
\text { phase based on } \\
\text { BIM }\end{array}$ & $\begin{array}{c}Z_{4} \text { : } \\
\text { combining } \\
\text { with other } \\
\text { technologies }\end{array}$ & $\begin{array}{l}\text { Combine BIM } \\
\text { and 3D laser } \\
\text { scanning } \\
\text { technology }\end{array}$ & $\begin{array}{l}3.2 .2 \\
3.3 .4\end{array}$ & [76] \\
\hline $\begin{array}{l}\text { Environmental } \\
\text { performance } \\
\text { assessment }\end{array}$ & $\begin{array}{c}X_{2}: \\
\text { convenience } \\
\text { of information } \\
\text { sharing and } \\
\text { exchange }\end{array}$ & $\begin{array}{c}\text { Create BIM } \\
\text { models and } \\
\text { calculate relevant } \\
\text { data }\end{array}$ & $\begin{array}{c}Y_{1} \text { : planning } \\
\text { and design } \\
\text { phase based on } \\
\text { BIM }\end{array}$ & $\begin{array}{l}Z_{1}: \text { reducing } \\
\text { energy } \\
\text { consumption }\end{array}$ & $\begin{array}{l}\text { Assess } \\
\text { environmental } \\
\text { performance of } \\
\text { the building }\end{array}$ & 3.3 .1 & {$[90,91]$} \\
\hline
\end{tabular}

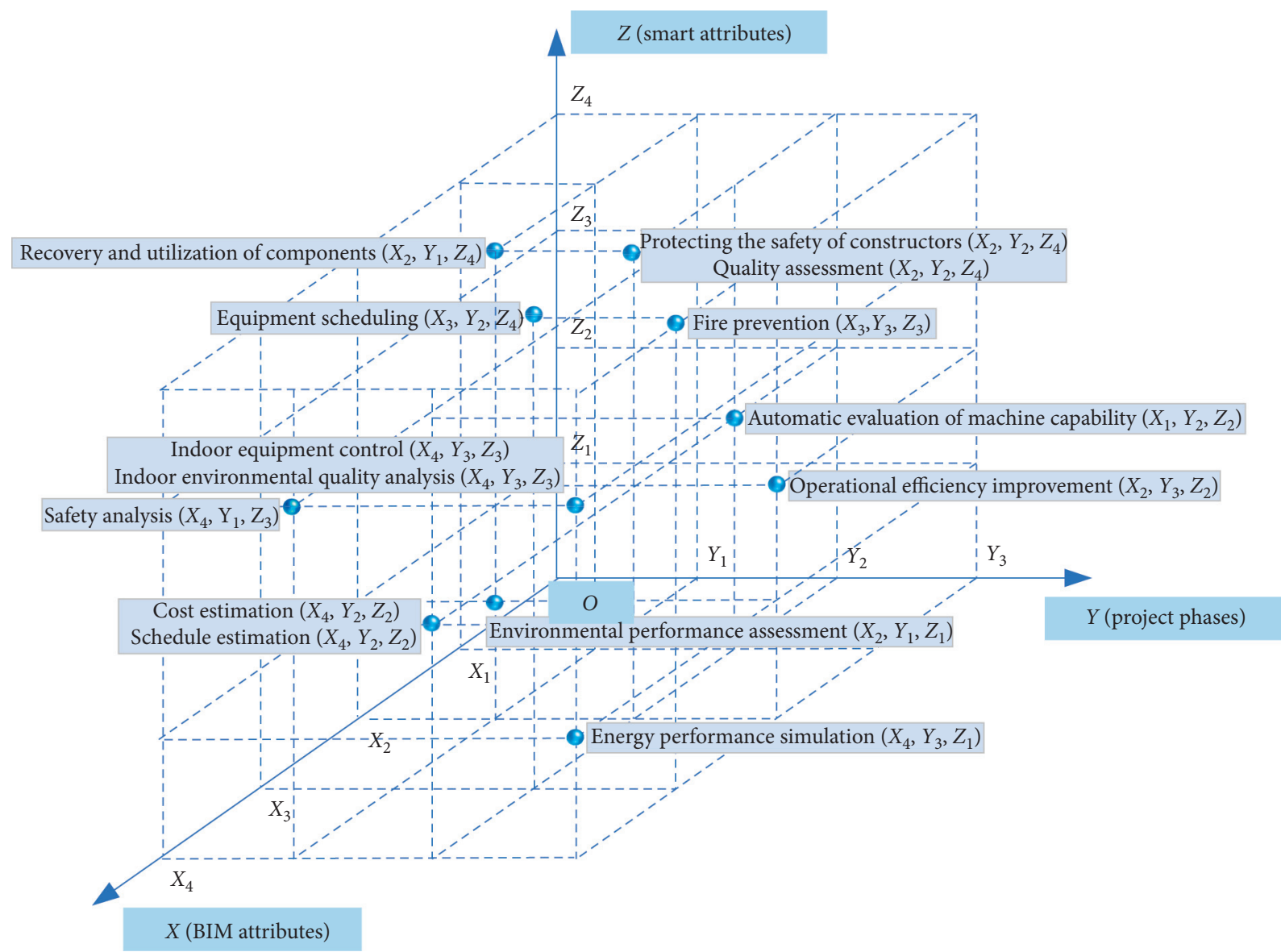

Figure 7: The cross-analysis of BIM attributes $(X)$, project phases $(Y)$, and smart attributes $(Z)$.

$\left(X_{2}\right)$ [51]. The BIM platform can be combined with WSN, IoT, and other technologies $\left(Z_{4}\right)$ to monitor construction site information in real time during the construction phase $\left(Y_{2}\right)$ to avoid hazardous situations (hypoxia and extreme temperature) in a confined space environment [51, 73]. The combination of BIM and other technologies promotes the development of the visibility and traceability of the BIM platform and ensures the safety of construction personnel on the construction site, thereby achieving safe construction.

3.4.5. Equipment Scheduling. During the construction process $\left(Y_{2}\right)$, equipment information is stored on the BIM model so that the construction site can be effectively 
visualized $\left(X_{3}\right)$. Collecting and integrating RFID data into the BIM system have the advantage of facilitating the dynamic adjustment of operation and equipment scheduling $\left(Z_{4}\right)[52,99]$. The BIM platform can combine RFID technology to realize real-time synchronization of equipment information, which is convenient for inspectors to quickly and accurately calculate the best path for each designated equipment and to arrange resources reasonably.

3.4.6. Safety Analysis. In the design phase $\left(Y_{1}\right)$, BIM can be used to graphically visualize physical entities and conduct a static and dynamic security analysis of the surrounding environment of smart buildings $\left(X_{4}\right)$ [55]. The building designers use the BIM platform to evaluate building safety design and safety monitoring systems, which can improve building safety significantly and protect users from potential hazards $\left(Z_{3}\right)$. Thus, safety analysis integrated with BIM can overcome smart buildings' safety problems caused by design defects and material selection errors to ensure the safety of smart buildings in the later phases [58].

3.4.7. Cost Estimation. In the construction phase $\left(Y_{2}\right)$, different materials, costs of machinery and labor, and other financial information are recorded in the BIM model to facilitate the estimation of the cost of earthwork $\left(X_{4}\right)$ $[56,57]$. With the help of building information stored in the BIM platform, the project material cost, mechanical cost, labor cost, and other costs can be clarified and applied in further overall cost management $\left(Z_{2}\right)$. Cost estimation based on the BIM model can reasonably control the project cost of smart construction projects and ensure the economic benefits of the project.

3.4.8. Schedule Estimation. In the construction phase $\left(Y_{2}\right)$, managers use BIM attributes $\left(X_{4}\right)$ to automatically extract the planned information of the construction task and exchange the current construction progress information with key personal [57]. Automatically outputting the construction schedule to estimate the construction schedule can effectively guarantee the economic benefits of smart building projects and promote the realization of smart attributes $\left(Z_{2}\right)$. The construction schedule estimation based on BIM technology can reduce the impact of schedule extension and ensure the timely delivery of the project [74].

3.4.9. Energy Performance Simulation. The energy-related data stored in the BIM database can be used to simulate the energy performance of the entire building, such as the lighting, heating, and ventilation $\left(X_{4}\right)$. Through analyzing the building's physical characteristics, building design standards, and operation and maintenance schedules, BIMbased energy performance simulation can effectively evaluate the rationality of building space occupation and lighting [54]. Then, by comparing and analyzing the data extracted from BIM and the data of the current building operation condition $\left(Y_{3}\right)$, the building energy monitoring and management capabilities can be improved to effectively reduce building energy consumption $\left(Z_{1}\right)$ [86].

3.4.10. Indoor Equipment Control. The BIM-based virtual environment involves user information in the current building environment, which is conducive to simulating the user's daily activities $\left(X_{4}\right)$ [59]. In the smart building operation and maintenance phase $\left(Y_{3}\right)$, the BIM-based virtual environment can help end-users experience their daily activities in a virtual environment and effectively control indoor equipment $\left(Z_{3}\right)$. The indoor equipment control system based on the BIM platform allows users to remotely turn on or turn off the equipment, effectively reducing energy consumption and improving the user comfort to achieve a state of smart life.

3.4.11. Indoor Environmental Quality Analysis. The smart building energy management system can perform real-time energy analysis $\left(X_{4}\right)$ by using BIM and smart sensors [95]. Energy simulation analysis (e.g., thermal comfort, acoustic comfort, lighting, and air quality) in the operation and maintenance phase of smart buildings $\left(Y_{3}\right)$ helps to improve indoor environmental quality and user comfort $\left(Z_{3}\right)$ [95]. Optimizing environmental parameters not only provides the foundation for studying the physical and operational properties of smart building systems but also contributes to improving user satisfaction related to indoor environmental factors [95].

3.4.12. Recovery and Utilization of Components. The data stored in the BIM platform enable designers and other managers to track and locate all the components for the actual building during the design phase $\left(Y_{1}\right)$ and promote the exchange and sharing of information $\left(X_{2}\right)$ [71]. The data from RFID tags can be integrated into BIM and then dynamically updated according to the unique recognition ability of RFID technology $\left(Z_{4}\right)$ [71]. Based on BIM and RFID technology, the recycling and utilization of components are realized, and the rational use of building resources is helpful to reduce project costs.

3.4.13. Quality Assessment. As a central data repository, the construction workers can use BIM to store and retrieve related facility information $\left(X_{2}\right)$ during the construction process $\left(Y_{2}\right)$ [76]. The relevant parameters collected by 3D laser scanning are imported into the BIM model to update the parameter of the building component for the as-is model $\left(Z_{4}\right)$. Based on BIM and 3D laser scanning technology, the size and surface quality of precast concrete components can be independently evaluated during the construction stage, which ensures the quality of the whole construction [76].

3.4.14. Environmental Performance Assessment. In the design phase $\left(Y_{1}\right)$, the designer creates a BIM model and calculates related building parameters to provide reliable data for the evaluation of the smart building environmental 
performance $\left(X_{2}\right)$ [24]. The intelligent green building rating (iGBR) framework supported by a semantic and social approach facilitates preliminary and continuous rating of building design to achieve smartness in energy consumption reduction $\left(Z_{1}\right)$ [90]. Environmental performance assessment based on BIM technology improves the efficiency of the assessment process and promotes the green and sustainable development of smart buildings.

\section{Research Gaps and Research Trends Smart Buildings Based on BIM}

In the process of analyzing the nexus of BIM and smart building, this paper finds the research gap in the field of BIM and smart building. The proposed research gap may become the research trend in the future. This paper presents a framework that links existing research gaps with research trends (see Figure 8). According to Section 3.1, this paper finds that BIM can provide the functions of information exchange and sharing, but the interoperability of BIM software needs to be improved. According to Section 3.2, this paper finds that the research phases and research objects of BIM technology in the field of smart buildings are constantly expanding. BIM technology is not only applied to the planning and design phase and the construction phase of smart buildings but also gradually applied to the operation and maintenance phase of smart buildings. And BIM is not only applied to the field of housing construction but also gradually applied to the field of transportation infrastructure. According to Section 3.3, this paper finds that the economic benefits brought by BIM projects are not clear. The main reason for unclear economic benefits is that the use of BIM technology will increase the cost of technology and personnel training, while reducing the cost of resource use, and the time cost brought by BIM technology cannot be quantified. In addition, the integration of BIM with IoT, RFID, and other technologies faces challenges such as unsmooth data format conversion and difficulty in updating models.

4.1. Insufficient Software Interoperability. The information exchange among different software is inevitable in each project phase of smart buildings. Interoperability is of great significance to facilitate the exchange of information among various BIM platforms (such as Revit and Tekla), enterprise systems, and smart components [48]. As Lilis and Kayal [100] pointed out, well-developed software interoperability can reduce the total project cost and shorten the return on investment time significantly. However, achieving well-developed software interoperability is accompanied by high project costs, such as the time and funds required for development [101].

Many studies have adopted semantic applications to solve interoperability problems [91]. Dibley et al. [102] emphasized the importance of improving the semantic interoperability among changing product information definitions in facility management. In an early study, Halfawy and Froese [62] proposed a standard data model for multiple building objects to enable the system to share the definition and semantics of objects, thereby improving software interoperability. Currently, Industry Foundation Class (IFC) provides a solid foundation for BIM interoperability, and most BIM applications use IFC as the data exchange standard [93]. For example, Akinade et al. [103] used IFC (ISO 16739:2013), IFD (ISO 12006eb:2007), IDMs (ISO 29481e1: 2010), and other standards to achieve the seamless exchange of information to coordinate with other software and overcome the barriers of interoperability. Li et al. [48] proposed that interoperability tools based on standard data patterns and IFC could be used to improve information exchange. Tang et al. [46] defined an IFC subset pattern so that building automation system (BAS) information can be represented in the IFC data model, and information can be exchanged at various project phases through BIM tools.

However, the above studies have their limitations, and a large number of BIM applications still suffer from insufficient interoperability. The root cause of insufficient interoperability of BIM software is the inconsistency of relevant standards of BIM software, such as data exchange format and data model. The IFCs specification is an open data file format that supports information storage, data sharing, and exchange between a wide range of software. Even if IFC is used, different BIM software that does not export IFC in a consistent way also impedes the free flow of information. Therefore, this study suggests that BIM software standards should consider multiple nexus dimensions, including the different project phases and various smartness attributes. As described in Section 3.2, BIM applications are required to achieve different functions in different project phases, such as collision prevention in the construction phase and fire hazard in the operation phase $[50,52]$. The distinct characteristics of those applications pose challenges for the unified IFC standard. Thus, considering the demand of the whole smart building lifecycle, instead of the individual BIM functions in a single phase, could potentially set the practical open IFC standard for BIM applications interoperability in smart buildings.

4.2. Limited BIM Applications in Operation and Refurbishment Phase. Most BIM research studies in the field of smart buildings focus on the planning, design, and construction phases [80]. Compared with the planning, design, and construction phases, the operation and maintenance phase of smart buildings consumes much energy and involves numerous construction activities, making management more complicated and diversified. With the mature application of BIM technology in the building design and construction phases, more managers have begun to explore the advantages of BIM in the operation and maintenance phase. Applications of BIM in the operation and maintenance phase involve emergency management [50], indoor environmental quality management [60], energy consumption management [95], indoor electrical control [80], but the research is still limited. Few studies focus on BIM applications in hazardous goods management, claims management, and construction waste management. It should be 

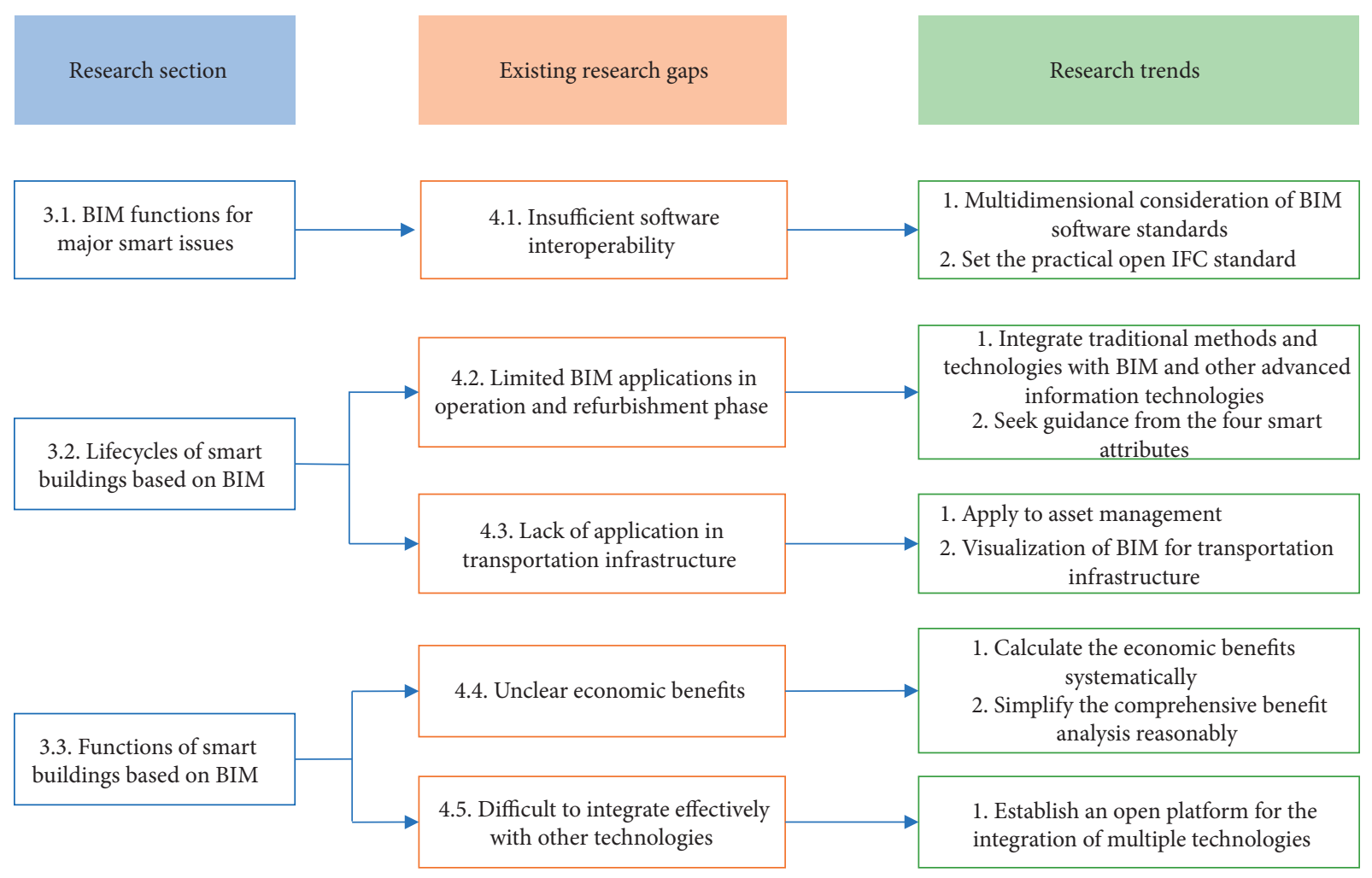

FIGURE 8: Research framework linking existing study areas to future directions.

noted that BIM technology can also help the facility management become automated and intelligent in the operation and maintenance phase and provide efficient and environmentally friendly services for residents [104].

According to the discussion of smartness in Section 3.3, it could be concluded that the BIM application has been infused with other advanced information technologies to improve living comfort and operational efficiency. Many innovative smart applications have been developed and transform the designing and construction phase, such as the IoT application in the prefabricated material construction [73]. Therefore, the traditional methods and technologies in the operation and maintenance phase could also evolve with the integrated BIM and other advanced information technologies. Future research of expanding the BIM application in the operation and maintenance phase could seek guidance from the four smart attributes.

\subsection{Lack of Application in Transportation Infrastructure.} Bridges, highways, and airports are all major infrastructures that make up the transportation system, and they are also essential assets of smart buildings. There have been studies on the application of BIM in the field of transportation infrastructure. For example, Marzouk and Hisham [56] introduced the cost and time management of BIM in bridge engineering. Kim et al. [57] applied BIM technology to highway projects, developed an object-based smart model, and obtained cost and schedule estimates automatically in the model. Lin et al. [93] proposed a smart data retrieval and representation method for cloud BIM applications and applied it to the construction of the Kunming Airport terminal. In a more recent study, Keskin and Salman [47] proposed a new method to guide the management of airport operators with BIM as the center research studies should pay more attention to BIMbased small airport projects and further determine the procedures related to BIM implementation in the airport operation process $[47,65]$. However, most of these studies are still in the stage of proposing the framework. In the future, more reliable work will be required to test, verify, and finally apply the proposed BIM-based smart transportation infrastructure implementation plan.

The transportation industry has also experienced the transformation process of the integration of automation technologies and multiple smart technologies [105]. The research on transportation technologies also seeks similar goals, such as optimization of operation scheduling, reducing carbon emission, and improvement of customer satisfaction $[47,56,57]$. As the BIM application in the transportation infrastructure is still in the early stage, future research could consider applying the BIM attributes summarized in the nexus of BIM and smart building applications to the asset management aspects. One possible application could be visualization facilitated with BIM for transportation infrastructure since the visualization of the building environment has proven to be effective in user interaction of equipment scheduling and build performance assessment $[49,52,77,99]$.

4.4. Unclear Economic Benefits. Existing studies have explored the cost input of BIM projects, but few studies have paid attention to the economic benefits brought by cost 
input. The actual economic benefits of the project should be based on the consideration of cost, time, project quality, and other factors. First, a fundamental challenge of BIM applications is the high initial costs of BIM implementation. As mentioned by Shahi et al. [106], BIM software, hardware, and technical training lead to an increase in the total cost of the project. Secondly, apart from those economic costs, smart building projects with BIM technology have to take project time into consideration, which is hard to estimate. Most construction workers have not received adequate education and training and do not understand BIM technology [74]. Construction enterprises should arrange technical training courses to help construction personnel familiar with the specific operation. Besides, considering the steep learning curve, the time cost of construction personnel to learn new technologies must be considered in the total project cost [45, 107]. Third, BIM-based smart building projects also have incomplete cost considerations. For example, Marzouk and Hisham [56] only considered the direct costs (materials, labor, and equipment) without considering indirect costs (management, insurance, and emergency) in the process of estimating the project cost.

Studies have been conducted to propose solutions to reduce the cost of BIM usage and improve project economics. For example, Fountain and Langar [108] suggested that companies could consider using outsourced BIM services provided by specialist information technology (IT) companies rather than using in-house BIM personnel to create and apply their BIM models, resulting in benefits such as reduced costs and improved business performance. Lu et al. [109] also suggested that contractors can compare different options by considering different designs, overdrafts, and interest rates and decide how to finance the overdraft costs for the smooth management of the project.

The economic benefit requires further comprehensive and quantitative study, which included multiple aspect benefits such as equipment, human, material, taxes, and other fees. The multiple BIM functions and technologies integrated into the smart building project make the analysis even more challenging. Thus, the paper suggests that the economic benefit might be systematically calculated following the dimensions identified in the nexus, namely, BIM attributes, project phases, and smart attributes. As shown in Table 5, different smart functions and integrated technologies are applied in the corresponding project phases; thus, the benefits analysis could be divided into subcategories to reasonably simplify the comprehensive benefit analysis.

\subsection{Difficult to Integrate Effectively with Other Technologies.} With the improvement of living standards, people have higher requirements for smart buildings. At present, using a specific technology alone cannot satisfy the current requirement of smart buildings. The BIM platform is integrating more and more smart applications [104]. For instance, Kim et al. [76] proposed that, in the process of evaluating concrete components using BIM and 3D laser scanning technology, the accuracy of evaluation and the efficiency of data storage should be further improved. Li et al.
[74] combined RFID and BIM to reduce construction risks and improve construction progress and then considered the introduction of fault-tolerant technology to eliminate incorrect operations in future research. Rashid et al. [80] proposed to integrate more complex filtering technology on the original BIM and IoT integrated platform in the future to obtain more accurate indoor positioning. Therefore, the comprehensive application of BIM in smart architecture requires a combination of different technologies. However, the high-level integration between BIM and various information technologies faces multiple problems, such as unsmooth data format conversion, difficulty in updating models, and obtaining real-time information.

Future research studies can consider using the BIM platform to build an open platform synchronized with different information sources such as wireless sensors and building automation systems [97]. The open BIM platform needs to consider the BIM attributes in the nexus and identify the challenge of integration from multiple aspects, such as the data transmission and integration, visualization, and analysis functions. To promote the full automation of smart buildings, the open BIM platform might consider multiple advanced information technologies from the crossanalysis, including wireless sensor network, cloud computing, and artificial intelligence.

In summary, based on the discussion of existing research gaps, there are still many directions to be explored in the research of smart buildings based on BIM technology. The future research directions proposed for the smart building applications could not be achieved only with BIM technologies but require further exploration in integrating BIM and other advanced information technologies in various disciplines.

\section{Conclusion}

The rise of BIM technology opens up a new horizon for the development of smart buildings. This paper reviews related journal articles on the BIM applications in smart buildings and also consults related BIM reports and guidelines. This paper identifies and analyzes the nexus of BIM and smart buildings from three dimensions: BIM attributes, project phases, and smart attributes. The identification of nexus dimensions reveals multiple essential and related characteristics of the BIM application in the smart building. The cross-analysis further identifies the key attributes in various application studies to guide the specific smart function research. This study's outcome would contribute to improving the smartness of the BIM application in terms of comprehensive function design, whole life cycle management, and smart technology integration.

This paper summarizes the three main aspects of the BIM applications in smart buildings: (1) the advantages of BIM in solving issues related to smart buildings; (2) applicability of BIM in all stages of the life cycle of smart buildings; and (3) smart building functions that BIM can achieve. The application advantages of BIM in the field of smart buildings have four aspects, including the integration of BIM and other systems, the convenience of information 
sharing and exchange, the visualization of the whole process and results, and the analysis and simulation of building functions. BIM is mainly applied to the planning, design, and construction phases of smart buildings, and the potential value of the operation and maintenance phase is gradually recognized. Smart building functions that BIM can achieve include reducing energy consumption, increasing economic benefits, improving user quality of life, and integrating other information technologies to enhance building automation.

Although BIM has injected infinite power into the development of smart buildings, it faces several challenges in the application process. Combining the current application status of BIM in smart buildings, this paper identifies five significant research gaps that need to be addressed in future research, including (1) insufficient software interoperability; (2) limited BIM applications in the operation and maintenance phase; (3) lack of applications in the field of transportation infrastructure; (4) unclear economic benefits; and (5) difficulty in integrating BIM with other technologies effectively.

\section{Data Availability}

The data used to support the findings of this study are available from the corresponding author upon request.

\section{Conflicts of Interest}

The authors declare that there are no conflicts of interest regarding the publication of this paper.

\section{Acknowledgments}

This work was supported by the Provincial Key Research and Development Project of Liaoning Province (2020JH2/ 10100042).

\section{References}

[1] E. Papadonikolaki, C. van Oel, and M. Kagioglou, "Organising and managing boundaries: a structurational view of collaboration with building information modelling (BIM)," International Journal of Project Management, vol. 37, no. 3, pp. 378-394, 2019.

[2] B. Qolomany, A. Al-Fuqaha, A. Gupta et al., "Leveraging machine learning and big data for smart buildings: a comprehensive survey," IEEE Access, vol. 7, pp. 90316-90356, 2019.

[3] J. Heaton, A. K. Parlikad, and J. Schooling, "Design and development of BIM models to support operations and maintenance," Computers in Industry, vol. 111, pp. 172-186, 2019.

[4] A. Ghaffarianhoseini, J. Tookey, A. Ghaffarianhoseini et al., "Building information modelling (BIM) uptake: clear benefits, understanding its implementation, risks and challenges," Renewable and Sustainable Energy Reviews, vol. 75, pp. 1046-1053, 2017.

[5] K. Lee and S. Choo, "A hierarchy of architectural design elements for energy saving of tower buildings in Korea using green BIM simulation," Advances in Civil Engineering, vol. 2018, Article ID 7139196, 13 pages, 2018.

[6] M. Jia, A. Komeily, Y. Wang, and R. S. Srinivasan, "Adopting internet of things for the development of smart buildings: a review of enabling technologies and applications," Automation in Construction, vol. 101, pp. 111-126, 2019.

[7] A. P. Plageras, K. E. Psannis, C. Stergiou, H. Wang, and B. B. Gupta, "Efficient IoT-based sensor BIG data collectionprocessing and analysis in smart buildings," Future Generation Computer Systems, vol. 82, pp. 349-357, 2018.

[8] T. Mazars and A. Francis, "Chronographical spatiotemporal dynamic 4D planning," Automation in Construction, vol. 112, Article ID 103076, 2020.

[9] M. Sandberg, J. Mukkavaara, F. Shadram, and T. Olofsson, "Multidisciplinary optimization of life-cycle energy and cost using a BIM-based master model," Sustainability, vol. 11, no. $1,2019$.

[10] T. Gerrish, K. Ruikar, M. Cook, M. Johnson, M. Phillip, and C. Lowry, "BIM application to building energy performance visualisation and management: challenges and potential," Energy and Buildings, vol. 144, pp. 218-228, 2017.

[11] X. Gao and P. Pishdad-Bozorgi, "BIM-enabled facilities operation and maintenance: a review," Advanced Engineering Informatics, vol. 39, pp. 227-247, 2019.

[12] A. Ghaffarianhoseini, U. Berardi, H. AlWaer et al., "What is an intelligent building? Analysis of recent interpretations from an international perspective," Architectural Science Review, vol. 59, no. 5, pp. 338-357, 2015.

[13] W. M. Kroner, "An intelligent and responsive architecture," Automation in Construction, vol. 6, no. 5-6, pp. 381-393, 1997.

[14] O. Omar, "Intelligent building, definitions, factors and evaluation criteria of selection," Alexandria Engineering Journal, vol. 57, no. 4, pp. 2903-2910, 2018.

[15] T. A. Nguyen and M. Aiello, "Energy intelligent buildings based on user activity: a survey," Energy and Buildings, vol. 56, pp. 244-257, 2013.

[16] J. Li, "Smart building research based on BIM," in Proceedings of the 5th International Conference on Machinery, Materials and Computing Technology (ICMMCT 2017), Beijing, China, March 2017.

[17] U. Isikdag and J. Underwood, "Two design patterns for facilitating building information model-based synchronous collaboration," Automation in Construction, vol. 19, no. 5, pp. 544-553, 2010.

[18] K. Barlish and K. Sullivan, "How to measure the benefits of BIM-a case study approach," Automation in Construction, vol. 24, pp. 149-159, 2012.

[19] X. Yin, H. Liu, Y. Chen, Y. Wang, and M. Al-Hussein, “A BIM-based framework for operation and maintenance of utility tunnels," Tunnelling and Underground Space Technology, vol. 97, Article ID 103252, 2020.

[20] N. Attoue, I. Shahrour, and R. Younes, "Smart building: use of the artificial neural network approach for indoor temperature forecasting," Energies, vol. 11, no. 2, p. 395, 2018.

[21] Y. Zong, W. Su, J. Wang et al., "Predictive control for smart buildings to provide the demand side flexibility in the multicarrier energy context: current status, pros and cons, feasibility and barriers," in Innovative Solutions for Energy Transitions, J. Yan, Ed., pp. 3026-3031, Elsevier, Amsterdam, Netherlands, 2019.

[22] P. Kochovski and V. Stankovski, "Supporting smart construction with dependable edge computing infrastructures 
and applications," Automation in Construction, vol. 85, pp. 182-192, 2018.

[23] Z. Pezeshki, A. Soleimani, and A. Darabi, "Application of BEM and using BIM database for BEM: a review," Journal of Building Engineering, vol. 23, pp. 1-17, 2019.

[24] S. Azhar, "Building information modeling (BIM): now and beyond," Australasian Journal of Construction Economics and Building, vol. 12, no. 4, pp. 15-28, 2012.

[25] M. F. Antwi-Afari, H. Li, E. A. Pärn, and D. J. Edwards, "Critical success factors for implementing building information modelling (BIM): a longitudinal review," Automation in Construction, vol. 91, pp. 100-110, 2018.

[26] X. Yin, H. Liu, Y. Chen, and M. Al-Hussein, "Building information modelling for off-site construction: review and future directions," Automation in Construction, vol. 101, pp. 72-91, 2019.

[27] Y. Song, X. Wang, Y. Tan et al., "Trends and opportunities of BIM-GIS integration in the architecture, engineering and construction industry: a review from a spatio-temporal statistical perspective," ISPRS International Journal of GeoInformation, vol. 6, no. 12, 2017.

[28] S. Winkelhaus and E. H. Grosse, "Logistics 4.0: a systematic review towards a new logistics system," International Journal of Production Research, vol. 58, no. 1, pp. 18-3, 2020.

[29] A. Kamyab, T. H. Maze, and R. R. Souleyrette, "Evaluation of vehicle-specific information in traffic control systems," Journal of Transportation Engineering, vol. 122, no. 6, pp. 421-429, 1996.

[30] X. Zheng, Y. Le, A. P. C. Chan, Y. Hu, and Y. Li, "Review of the application of social network analysis (SNA) in construction project management research," International Journal of Project Management, vol. 34, no. 7, pp. 1214-1225, 2016.

[31] B. de Vries, E. Allameh, and M. Heidari, "Smart-BIM (building information modeling)," Gerontechnology, vol. 11, no. 2, 2012.

[32] Y. Lu, Z. Wu, R. Chang, and Y. Li, "Building information modeling (BIM) for green buildings: a critical review and future directions," Automation in Construction, vol. 83, pp. 134-148, 2017.

[33] F. Jalaei and A. Jrade, "Integrating building information modeling (BIM) and LEED system at the conceptual design stage of sustainable buildings," Sustainable Cities and Society, vol. 18, pp. 95-107, 2015.

[34] Öö Göçer, Y. Hua, and K. Göçer, “A BIM-GIS integrated preretrofit model for building data mapping," Building Simulation, vol. 9, no. 5, pp. 513-527, 2016.

[35] M. Oh, J. Lee, S. W. Hong, and Y. Jeong, "Integrated system for BIM-based collaborative design," Automation in Construction, vol. 58, pp. 196-206, 2015.

[36] M. Röck, A. Hollberg, G. Habert, and A. Passer, "LCA and BIM: visualization of environmental potentials in building construction at early design stages," Building and Environment, vol. 140, pp. 153-161, 2018.

[37] E. Kamel and A. M. Memari, "Review of BIM's application in energy simulation: tools, issues, and solutions," Automation in Construction, vol. 97, pp. 164-180, 2019.

[38] S. Pinheiro, R. Wimmer, J. O’Donnell et al., “MVD based information exchange between BIM and building energy performance simulation," Automation in Construction, vol. 90, pp. 91-103, 2018.

[39] Y. Zou, A. Kiviniemi, and S. W. Jones, "A review of risk management through BIM and BIM-related technologies," Safety Science, vol. 97, pp. 88-98, 2017.
[40] L. Ding, Y. Zhou, and B. Akinci, "Building information modeling (BIM) application framework: the process of expanding from $3 \mathrm{D}$ to computable $\mathrm{nD}$," Automation in Construction, vol. 46, pp. 82-93, 2014.

[41] H.-Y. Chong, C.-Y. Lee, and X. Wang, "A mixed review of the adoption of building information modelling (BIM) for sustainability," Journal of Cleaner Production, vol. 142, pp. 4114-4126, 2017.

[42] Alibaba Group, White Paper on Smart Buildings, G. Lu, Ed., Alibaba Group Real Estate Division Ali Research Institute, Hangzhou, China, 2017.

[43] J.-H. Woo and C. Menassa, "Virtual retrofit model for aging commercial buildings in a smart grid environment," Energy and Buildings, vol. 80, pp. 424-435, 2014.

[44] S. An, P. Martinez, M. Al-Hussein, R. Ahmad et al., "BIMbased decision support system for automated manufacturability check of wood frame assemblies," Automation in Construction, vol. 111, Article ID 103065, 2020.

[45] M. Marzouk and A. Othman, "Planning utility infrastructure requirements for smart cities using the integration between BIM and GIS," Sustainable Cities and Society, vol. 57, 2020.

[46] S. Tang, D. R. Shelden, C. M. Eastman, P. Pishdad-Bozorgi, $\mathrm{X}$. Gao et al., "BIM assisted building automation system information exchange using BACnet and IFC," Automation in Construction, vol. 110, Article ID 103049, 2020.

[47] B. Keskin and B. Salman, "Building information modeling implementation framework for smart airport life cycle management," Transportation Research Record, vol. 2674, no. 6, pp. 98-112, 2020.

[48] X. Li, G. Q. Shen, P. Wu, and T. Yue, "Integrating building information modeling and prefabrication housing production," Automation in Construction, vol. 100, pp. 46-60, 2019.

[49] K. K. Han and M. Golparvar-Fard, "Potential of big visual data and building information modeling for construction performance analytics: an exploratory study," Automation in Construction, vol. 73, pp. 184-198, 2017.

[50] M.-Y. Cheng, K.-C. Chiu, Y.-M. Hsieh, I.-T. Yang, J.-S. Chou, and Y.-W. Wu, "BIM integrated smart monitoring technique for building fire prevention and disaster relief," Automation in Construction, vol. 84, pp. 14-30, 2017.

[51] Z. Riaz, M. Arslan, A. K. Kiani, and S. Azhar, "CoSMoS: a BIM and wireless sensor based integrated solution for worker safety in confined spaces," Automation in Construction, vol. 45, pp. 96-106, 2014.

[52] S. Dutta, Y. Cai, L. Huang, J. Zheng et al., "Automatic replanning of lifting paths for robotized tower cranes in dynamic BIM environments," Automation in Construction, vol. 110, Article ID 102998, 2020.

[53] T. O. Olawumi and D. W. M. Chan, "Identifying and prioritizing the benefits of integrating BIM and sustainability practices in construction projects: a Delphi survey of international experts," Sustainable Cities and Society, vol. 40, pp. 16-27, 2018.

[54] B. Welle, Z. Rogers, and M. Fischer, "BIM-centric daylight profiler for simulation (BDP4SIM): a methodology for automated product model decomposition and recomposition for climate-based daylighting simulation," Building and Environment, vol. 58, pp. 114-134, 2012.

[55] S. Porter, T. Tan, T. Tan, and G. West, "Breaking into BIM: performing static and dynamic security analysis with the aid of BIM," Automation in Construction, vol. 40, pp. 84-95, 2014.

[56] M. Marzouk and M. Hisham, "Implementing earned value management using bridge information modeling," KSCE 
Journal of Civil Engineering, vol. 18, no. 5, pp. 1302-1313, 2014.

[57] H. Kim, Z. Shen, H. Moon, K. Ju, and W. Choi, "Developing a 3D intelligent object model for the application of construction planning/simulation in a highway project," Ksce Journal of Civil Engineering, vol. 20, no. 2, pp. 538-548, 2016.

[58] A. J.-P. Tixier, M. R. Hallowell, B. Rajagopalan, and D. Bowman, "Construction safety clash detection: identifying safety incompatibilities among fundamental attributes using data mining," Automation in Construction, vol. 74, pp. 39-54, 2017.

[59] M. Heidari, E. Allameh, B. de Vries, H. Timmermans, J. Jessurun, and F. Mozaffar, "Smart-BIM virtual prototype implementation," Automation in Construction, vol. 39, pp. 134-144, 2014.

[60] S. Habibi, "Smart innovation systems for indoor environmental quality (IEQ)," Journal of Building Engineering, vol. 8, pp. 1-13, 2016.

[61] A. Audier, J.-F. Lahet, and R. . d. Laubier, The BIM Revolution Comes to Building Materials, Boston Consulting Group, Boston, MA, USA, 2017.

[62] M. Halfawy and T. Froese, "Building integrated architecture/ engineering/construction systems using smart objects: methodology and implementation," Journal of Computing in Civil Engineering, vol. 19, no. 2, pp. 172-181, 2005.

[63] X. Yang, M. Hu, J. Wu, and B. Zhao, "Building-informationmodeling enabled life cycle assessment, a case study on carbon footprint accounting for a residential building in China," Journal of Cleaner Production, vol. 183, pp. 729-743, 2018.

[64] E. Forcael, A. Nope, R. García-Alvarado, A. Bobadilla, and C. Rubio-Bellido, "Architectural and management strategies for the design, construction and operation of energy efficient and intelligent primary care centers in Chile," Sustainability, vol. 11, no. 2, 2019.

[65] E. Hetemi, J. Ordieres-Mere, and C. Nuur, "An institutional approach to digitalization in sustainability-oriented infrastructure projects: the limits of the building information model," Sustainability, vol. 12, no. 9, 2020.

[66] M. M. Singh, A. Sawhney, and A. Borrmann, "Modular coordination and BIM: development of rule based smart building components," Procedia Engineering, vol. 123, pp. 519-527, 2015.

[67] A. A. Volkov and E. I. Batov, "Dynamic extension of building information model for "smart" buildings," Procedia Engineering, vol. 111, pp. 849-852, 2015.

[68] J. P. Liu, C. Xu, Z. Wu, and Y. F. Chen, "Intelligent rebar layout in RC building frames using artificial potential field," Automation in Construction, vol. 114, Article ID 103172, 2020.

[69] J. R. Lin and Y. C. Zhou, "Semantic classification and hash code accelerated detection of design changes in BIM models," Automation in Construction, vol. 115, Article ID 103212, 2020.

[70] E. T. A. Lin, G. Ofori, I. Tjandra, and H. Kim, "Framework for productivity and safety enhancement system using BIM in Singapore," Engineering Construction and Architectural Management, vol. 24, no. 6, pp. 1350-1371, 2017.

[71] D. Ness, J. Swift, D. C. Ranasinghe, K. Xing, and V. Soebarto, "Smart steel: new paradigms for the reuse of steel enabled by digital tracking and modelling," Journal of Cleaner Production, vol. 98, pp. 292-303, 2015.
[72] Z. Ma and Z. Liu, "BIM-based intelligent acquisition of construction information for cost estimation of building projects," Procedia Engineering, vol. 85, pp. 358-367, 2014.

[73] C. Z. Li, F. Xue, X. Li, J. Hong, and G. Q. Shen, "An internet of things-enabled BIM platform for on-site assembly services in prefabricated construction," Automation in Construction, vol. 89, pp. 146-161, 2018.

[74] C. Z. Li, R. Y. Zhong, F. Xue et al., "Integrating RFID and BIM technologies for mitigating risks and improving schedule performance of prefabricated house construction," Journal of Cleaner Production, vol. 165, pp. 1048-1062, 2017.

[75] H. W. Wang, J. R. Lin, and J. P. Zhang, "Work package-based information modeling for resource-constrained scheduling of construction projects," Automation in Construction, vol. 109, 2020.

[76] M.-K. Kim, J. C. P. Cheng, H. Sohn, and C.-C. Chang, "A framework for dimensional and surface quality assessment of precast concrete elements using BIM and 3D laser scanning," Automation in Construction, vol. 49, pp. 225-238, 2015.

[77] E. Krasny, S. Klarić, and A. Korjenić, "Analysis and comparison of environmental impacts and cost of bio-based house versus concrete house," Journal of Cleaner Production, vol. 161, pp. 968-976, 2017.

[78] F. Xue, W. Lu, K. Chen, and A. Zetkulic, "From semantic segmentation to semantic registration: derivative-free optimization-based approach for automatic generation of semantically rich as-built building information models from 3D point clouds," Journal of Computing in Civil Engineering, vol. 33, no. 4, 2019.

[79] K. Chen, W. Lu, F. Xue, P. Tang, and L. H. Li, “Automatic building information model reconstruction in high-density urban areas: augmenting multi-source data with architectural knowledge," Automation in Construction, vol. 93, pp. 22-34, 2018.

[80] K. M. Rashid, J. Louis, and K. K. Fiawoyife, "Wireless electric appliance control for smart buildings using indoor location tracking and BIM-based virtual environments," Automation in Construction, vol. 101, pp. 48-58, 2019.

[81] J. P. Liu, P. Liu, L. Feng, W. Wu, D. Li, and Y. F. Chen, "Automated clash resolution for reinforcement steel design in concrete frames via Q-learning and building information modeling," Automation in Construction, vol. 112, Article ID 103062, 2020.

[82] H. R. Shaker and S. Lazarova-Molnar, "A new data-driven controllability measure with application in intelligent buildings," Energy and Buildings, vol. 138, pp. 526-529, 2017.

[83] M. Azzi, H. Duc, and Q. P. Ha, "Toward sustainable energy usage in the power generation and construction sectors-a case study of Australia," Automation in Construction, vol. 59, pp. 122-127, 2015.

[84] K. I. Katsigarakis, G. D. Kontes, G. I. Giannakis, and D. V. Rovas, "Sense-think-act framework for intelligent building energy management," Computer-Aided Civil and Infrastructure Engineering, vol. 31, no. 1, pp. 50-64, 2016.

[85] C. Panteli, A. Kylili, and P. A. Fokaides, "Building information modelling applications in smart buildings: from design to commissioning and beyond: a critical review," Journal of Cleaner Production, vol. 265, Article ID 121766, 2020.

[86] H. U. Gökçe and K. U. Gökçe, "Holistic system architecture for energy efficient building operation," Sustainable Cities and Society, vol. 6, pp. 77-84, 2013.

[87] K. McGlinn, B. Yuce, H. Wicaksono, S. Howell, and Y. Rezgui, "Usability evaluation of a web-based tool for 
supporting holistic building energy management," Automation in Construction, vol. 84, pp. 154-165, 2017.

[88] S. Kaewunruen, P. Rungskunroch, and J. Welsh, "A digitaltwin evaluation of net zero energy building for existing buildings," Sustainability, vol. 11, no. 1, 2018.

[89] T. W. Kang and H. S. Choi, "BIM-based data mining method considering data integration and function extension," KSCE Journal of Civil Engineering, vol. 22, no. 5, pp. 1523-1534, 2018.

[90] D. X. Zhang, J. Zhang, J. Guo, and H. Xiong, "A semantic and social approach for real-time green building rating in BIMbased design," Sustainability, vol. 11, no. 14, 2019.

[91] S. H. Jiang, N. Wang, and J. Wu, "Combining BIM and ontology to facilitate intelligent green building evaluation," Journal of Computing in Civil Engineering, vol. 32, no. 5, 2018.

[92] W. Lu and T. Olofsson, "Building information modeling and discrete event simulation: towards an integrated framework," Automation in Construction, vol. 44, pp. 73-83, 2014.

[93] J.-R. Lin, Z.-Z. Hu, J.-P. Zhang, and F.-Q. Yu, "A naturallanguage-based approach to intelligent data retrieval and representation for cloud BIM," Computer-Aided Civil and Infrastructure Engineering, vol. 31, no. 1, pp. 18-33, 2016.

[94] K. Yang and S. B. Cho, "Towards sustainable smart homes by a hierarchical hybrid architecture of an intelligent agent," Sustainability, vol. 8, no. 10, 2016.

[95] S. Habibi, "Micro-climatization and real-time digitalization effects on energy efficiency based on user behavior," Building and Environment, vol. 114, pp. 410-428, 2017.

[96] S. Yamamura, L. Fan, and Y. Suzuki, "Assessment of urban energy performance through integration of BIM and GIS for smart city planning," Procedia Engineering, vol. 180, pp. 1462-1472, 2017.

[97] B. Dave, A. Buda, A. Nurminen, and K. Främling, "A framework for integrating BIM and IoT through open standards," Automation in Construction, vol. 95, pp. 35-45, 2018.

[98] S. Tang, D. R. Shelden, C. M. Eastman, P. Pishdad-Bozorgi, and X. Gao, "A review of building information modeling (BIM) and the internet of things (IoT) devices integration: present status and future trends," Automation in Construction, vol. 101, pp. 127-139, 2019.

[99] Y. H. Tsai, J. Wang, W.-T. Chien, C.-Y. Wei, X. Wang, and S.-H. Hsieh, "A BIM-based approach for predicting corrosion under insulation," Automation in Construction, vol. 107, 2019.

[100] G. Lilis and M. Kayal, "A secure and distributed message oriented middleware for smart building applications," $\mathrm{Au}$ tomation in Construction, vol. 86, pp. 163-175, 2018.

[101] A. Costin and C. Eastman, "Need for interoperability to enable seamless information exchanges in smart and sustainable urban systems," Journal of Computing in Civil Engineering, vol. 33, no. 3, 2019.

[102] M. Dibley, H. Li, Y. Rezgui, and J. Miles, “An ontology framework for intelligent sensor-based building monitoring," Automation in Construction, vol. 28, pp. 1-14, 2012.

[103] O. O. Akinade, L. O. Oyedele, S. O. Ajayi et al., "Designing out construction waste using BIM technology: stakeholders' expectations for industry deployment," Journal of Cleaner Production, vol. 180, pp. 375-385, 2018.

[104] J. Y. Xu, W. Lu, F. Xue, and K. Chen, "'Cognitive facility management': definition, system architecture, and example scenario," Automation in Construction, vol. 107, 2019.
[105] A. Costin, A. Adibfar, H. Hu, and S. S. Chen, "Building information modeling (BIM) for transportation infrastructure-literature review, applications, challenges, and recommendations," Automation in Construction, vol. 94, pp. 257-281, 2018.

[106] K. Shahi, B. Y. McCabe, and A. Shahi, "Framework for automated model-based e-permitting system for municipal jurisdictions," Journal of Management in Engineering, vol. 35, no. 6, 2019.

[107] T. O. Olawumi, D. W. M. Chan, J. K. W. Wong, and A. P. C. Chan, "Barriers to the integration of BIM and sustainability practices in construction projects: a Delphi survey of international experts," Journal of Building Engineering, vol. 20, pp. $60-71,2018$.

[108] J. Fountain and S. Langar, "Building information modeling (BIM) outsourcing among general contractors," Automation in Construction, vol. 95, pp. 107-117, 2018.

[109] Q. Lu, J. Won, and J. C. P. Cheng, "A financial decision making framework for construction projects based on $5 \mathrm{D}$ building information modeling (BIM)," International Journal of Project Management, vol. 34, no. 1, pp. 3-21, 2016. 